\title{
Impacts of climate change on temperature, precipitation and hydrology in Finland - studies using bias corrected Regional Climate Model data
}

\author{
T. Olsson ${ }^{1}$, J. Jakkila ${ }^{2}$, N. Veijalainen ${ }^{2}$, L. Backman ${ }^{1}$, J. Kaurola ${ }^{1}$, and B. Vehviläinen ${ }^{2}$ \\ ${ }^{1}$ Finnish Meteorological Institute, Erik Palménin aukio 1, 00101, Helsinki, Finland \\ ${ }^{2}$ Freshwater Centre, Finnish Environment Institute, Mechelininkatu 34a, P.O. Box 140, 00251, Helsinki, Finland
}

Correspondence to: T. Olsson (taru.olsson@ fmi.fi)

Received: 19 January 2015 - Published in Hydrol. Earth Syst. Sci. Discuss.: 3 March 2015

Revised: 11 June 2015 - Accepted: 23 June 2015 - Published: 24 July 2015

\begin{abstract}
Assessment of climate change impacts on climate and hydrology on catchment scale requires reliable information about the average values and climate fluctuations of the past, present and future. Regional climate models (RCMs) used in impact studies often produce biased time series of meteorological variables. In this study bias correction (BC) of RCM temperature and precipitation for Finland is carried out using different versions of the distribution based scaling (DBS) method. The DBS-adjusted RCM data are used as input of a hydrological model to simulate changes in discharges of four study catchments in different parts of Finland. The annual mean discharges and seasonal variation simulated with the DBS-adjusted temperature and precipitation data are sufficiently close to observed discharges in the control period 1961-2000 and produce more realistic projections for mean annual and seasonal changes in discharges than the uncorrected RCM data. Furthermore, with most scenarios the DBS method used preserves the temperature and precipitation trends of the uncorrected RCM data during 1961-2100. However, if the biases in the mean or the standard deviation of the uncorrected temperatures are large, significant biases after DBS adjustment may remain or temperature trends may change, increasing the uncertainty of climate change projections. The DBS method influences especially the projected seasonal changes in discharges and the use of uncorrected data can produce unrealistic seasonal discharges and changes. The projected changes in annual mean discharges are moderate or small, but seasonal distribution of discharges will change significantly.
\end{abstract}

\section{Introduction}

Climate in Finland is boreal with temperate and sub-arctic features and four distinct seasons (Castro et al., 2007; Jylhä et al., 2009a). Winters are mostly cold and snowy and summers rather short, cool and rainy. Precipitation is moderate in all seasons. Hydrology in Finland is characterized by seasonal variation with snow accumulation and low flow during winter, snowmelt with runoff peak in spring, another low flow season in summer and increasing runoffs towards autumn. Climate change is expected to significantly influence the hydrology in Finland. Climate zones are expected to shift towards the north during this century, and the prevailing climate type will become more temperate and wet (Jylhä et al., 2009a). According to Jylhä et al. (2009b) annual mean temperature is likely to increase by $3-6^{\circ} \mathrm{C}$ by the end of this century, compared to 1971-2000. Precipitation is expected to increase 12-22\% in Finland by the end of the century (Jylhä et al., 2009b), but the spatial distribution or the temporal cycle of the seasonal precipitation will not change significantly.

Changes in temperature will inevitably affect the snow and ice accumulation and melt processes as well as the extent of snow and ice cover. In southern Finland permanent snow cover will become rare by the end of the century (Ruosteenoja et al., 2011). Changes in temperature and precipitation and consequent changes in snow accumulation and melt will affect seasonal variation of river discharges and water levels of lakes. Because the temperature in winter will more frequently rise above zero degrees, winter discharges and water levels will increase, while spring snowmelt discharges decrease especially in southern and central Finland 
due to decreased snow accumulation (Vehviläinen and Huttunen, 1997; Veijalainen et al., 2010). The changes in river discharge and lake water levels will cause adaptation needs in water power production, flood protection and lake regulation (Veijalainen, 2012).

Regional and local climate change scenarios are needed for assessments of climate change impacts on hydrology and other sectors in Finland. The spatial resolution of global climate models $(\mathrm{GCM})(100-300 \mathrm{~km})$ is insufficient to simulate regional scale events that are needed to capture different weather phenomena in a catchment scale. Projections of GCMs can be dynamically downscaled with regional climate models (RCMs) to scales of $25-50 \mathrm{~km}$, which represents the Finnish catchment scales better. Though nested models are more computationally demanding, dependent on GCM forcing and need detailed surface data, they are able to produce more detailed information on temporal and spatial scales than GCMs (Hewitson and Crane, 1996). This information is necessary when RCM data are used as input for impact models such as hydrological models.

Although increased horizontal resolution can improve the simulation of regional and local climate features, RCMs still produce biases in the time series of climate variables (Christensen et al., 2008; Rauscher et al., 2010). RCMs are found to have lower skill to reproduce temperature and precipitation in colder regions (Teutschbein and Seibert, 2012) and have difficulties to reproduce realistic values near the coast line and lakes in Finland (Jylhä et al., 2009b). Hydrological simulations using the RCM data as direct input are sensitive to RCM biases (Wood et al., 2004), and especially regions such as Finland are sensitive to temperature bias, where seasonal snowpack causes a time shift in runoff generation (Wood et al., 2004; Veijalainen et al., 2012). Therefore, an efficient bias correction (BC) method for both precipitation and temperature should be applied to the RCM data.

Several approaches are available for adjusting RCM variables; these can be divided into delta change (DC) and BC methods. The DC approach adjusts observations with the RCM climate change signal, whereas the BC approach adjusts the daily RCM simulated variables based on the difference between observed and simulated climate in the control period. Compared to the DC method the BC approach usually better preserves the future variability in temperature and precipitation produced by the RCMs, enables representation of complex changes in climate related to changes in mesoscale weather conditions and enables transient scenarios instead of comparison between time slices (Graham et al., 2007; Lenderink et al., 2007; Beldring et al., 2008; Yang et al., 2010). Bias correction methods have been proved to improve daily mean, standard deviation (SD), and distribution of the RCM temperature and precipitation when compared to observed climate statistics (e.g. Yang et al., 2010; Teutschbein and Seibert, 2012; Räisänen and Räty, 2013; Räty et al., 2014).
In this paper, bias corrected RCM data sets of precipitation and temperature covering the area of Finland are produced. Two versions of a distribution based bias correction method are evaluated for temperature and precipitation. In addition, a simple mean bias correction is applied for daily wind speed and specific humidity, which are used in simulation of lake evaporation in the hydrological model. These bias corrected values are then used as input of the hydrological model to simulate discharges and their changes due to climate change in selected catchments. The goal is to evaluate the DBS method in climate change impact studies of river discharges in Finland. This article focuses on annual and seasonal mean values, while the second part of the study in a separate paper will focus on extremes, especially heavy precipitation and floods, and their changes.

\section{Materials and methods}

In this study, climate scenarios from RCMs are first bias corrected using observations of temperature, precipitation, wind speed and humidity and then used to produce hydrological scenarios for the study catchments (Fig. 1).

\subsection{Study catchments}

Four catchments located in different parts of Finland were selected as study catchments (Fig. 2). These represent different hydrological regions in Finland. Loimijoki (Maurialankoski observation station, catchment area $2650 \mathrm{~km}^{2}$; lake percentage 3.1) is a medium sized river with high proportion of cultivated area on clay soils. Nilakka (catchment area $2160 \mathrm{~km}^{2}$; $18 \%$ lake percentage) and Lentua $\left(2050 \mathrm{~km}^{2} ; 13 \%\right)$ observation stations are located at lake outlets in central Finland characterized by numerous lakes. Ounasjoki (Marraskoski observation station, $\left.12300 \mathrm{~km}^{2} ; 2.6 \%\right)$ is a large river in northern Finland (Fig. 2) (Korhonen and Kuusisto, 2010). All the study catchments have long water level and discharge observation series, the longest from 1912 onwards (Lentua) and the shortest from 1935 onwards (Loimijoki).

Annual mean runoff in the study catchments varies from 280 to $370 \mathrm{~mm}$. Runoff has a distinct seasonal variation with low values during winter and summer and a maximum in spring due to snowmelt. The average maximum snow water equivalent varies from 80 to $100 \mathrm{~mm}$ in the southern catchment (Loimijoki) to $180 \mathrm{~mm}$ in the northern Ounasjoki catchment (Perälä and Reuna, 1990). Annual soil and lake evaporation gradually decrease from southern Loimijoki (soil $400 \mathrm{~mm}$; lake $540 \mathrm{~mm}$ ) to northern Ounasjoki (soil $220 \mathrm{~mm}$; lake $310 \mathrm{~mm}$ ) (Hyvärinen et al., 1995). Autumn precipitation causes a second runoff peak, which is usually smaller than the spring peak. The spring floods are more pronounced in northern and central Finland (Ounasjoki, Lentua, Nilakka), while in southern Finland (Loimijoki) heavy rains in sum- 


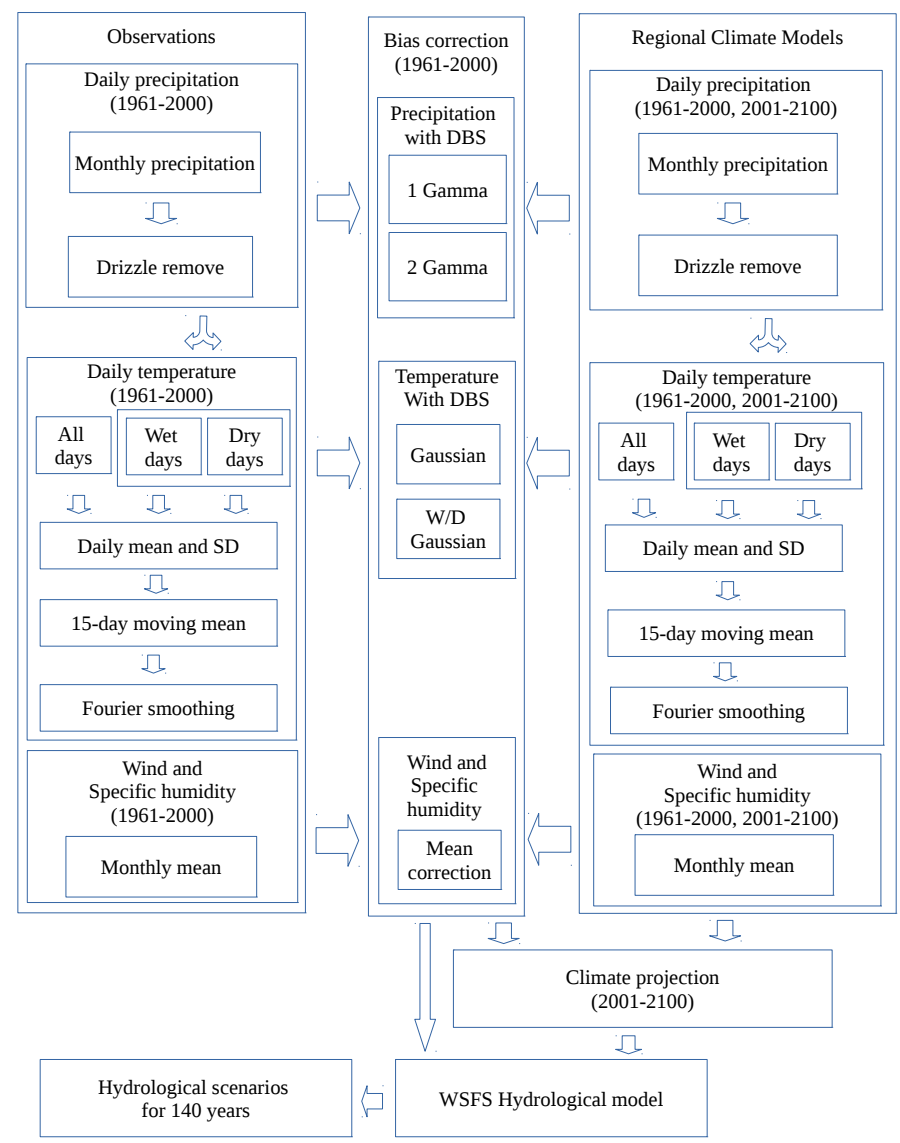

Figure 1. Schematic presentation of application procedure used in this study for hydrological modelling of climate change impact with bias corrected RCM data.

mer and autumn or rains with snowmelt in winter may cause major floods as well.

\subsection{Observations and RCM data}

Bias corrections were calculated for the entire Finland including transboundary watershed areas in Norway, Sweden and Russia. The gridded data sets needed for the bias correction were calculated using observations from approximately 190 stations with daily temperature measurements at $2 \mathrm{~m}$ height and 250 stations with daily precipitation measurements from the Finnish Meteorological Institute (FMI). Additional observations from 11 temperature and 16 precipitation observation stations in Norway, Sweden and Russia were provided by the Norwegian Meteorological Institute, the Swedish Meteorological and Hydrological Institute (SMHI) and the Hydrometeorological Centre of Russia. Observations from 1961 to 2000 were used although the observation network varies during this period.

Gauge precipitation observations especially for snowfall contain various systematic measurement errors (Førland et al., 1996; Taskinen, 2015), which need to be corrected before they can be used for bias correction of RCM data. The correction of precipitation measurements consisted of the exposure method for aerodynamic correction as well as wetting and evaporation corrections (Taskinen, 2015). The areal values of the meteorological observations are calculated for each sub-basin of the hydrological model from three closest observation stations by inverse distance weighting taking into account the elevation differences. The areal values were converted to the same regular $0.25^{\circ}$ lat $\times 0.25^{\circ}$ long grid as the RCM data.

The observations of relative humidity at $2 \mathrm{~m}$ and wind speed at $10 \mathrm{~m}$ are used in the simulation of lake evaporation, which is an important hydrological variable for catchments in the lake area. The areal values are calculated in a similar way as temperature and precipitation and the effect of fetch to the wind speed on a lake is calculated as in Resio and Vincent (1977).

Five climate scenarios are used from four different RCMs forced with four different GCMs as given in Table 1 with acronyms used hereinafter. Selected RCM projections are the same as used in Veijalainen et al. (2012), excluding RCAECHAM5 (see Table 4), to enable comparison of results. The data were retrieved from the ENSEMBLE (ENSEMBLEbased Predictions of Climate Changes and their Impacts) 


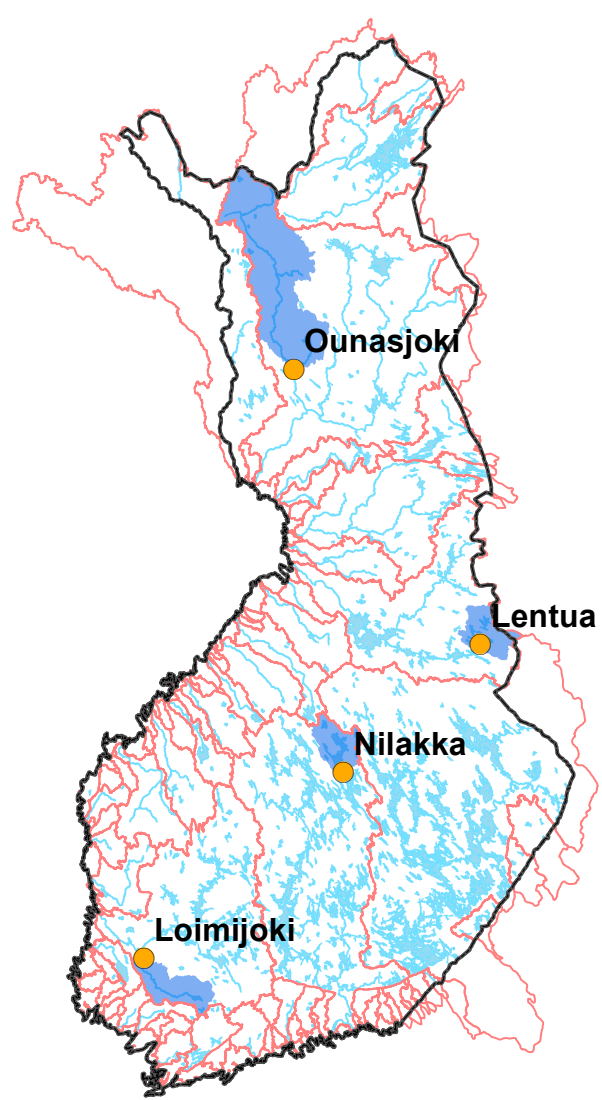

Figure 2. Map of the study catchments.

Table 1. Regional climate model (RCM) data used in this study.

\begin{tabular}{llll}
\hline Name/Acronym & RCM & GCM & $\begin{array}{l}\text { Emission } \\
\text { scenario }\end{array}$ \\
\hline HIRHAM-A & HIRHAM5 & ARPEGE & A1B \\
HIRHAM-B & HIRHAM5 & BCM & A1B \\
REMO & REMO & ECHAM5 & A1B \\
RCA & RCA & ECHAM5 & A1B \\
HadRM & HadRM3Q0 & HadCM3Q0 & A1B \\
\hline
\end{tabular}

HIRHAM5 is a combination of the HIRLAM (High Resolution Limited Area Model) and ECHAM; REMO is the Max Planck Institute's REgional MOdel; RCA is the Rossby Center Regional Atmospheric Model; HadRM3Q0 is the Hadley Centre Regional Model, version 3 (normal sensitivity);

ARPEGE is the Action de Recherche Petite Echelle Grande Echelle; BCM is the Bergen Climate Model; ECHAM5 is the European Centre Hamburg model, version 5; HadCM3Q0 is the Hadley Centre Coupled Model, version 3 (normal sensitivity).

project's research team 3 database (ensemblesrt3.dmi.dk; van der Linden and Mitchell, 2009). The GCMs were run under historic (1961-2000) and with A1B scenario (2001-2100) forcing. The GCM output was then used as boundary conditions to force RCMs over a common European domain in a regular $0.25^{\circ}$ lat $\times 0.25^{\circ}$ long grid (van der Linden and Mitchell, 2009).
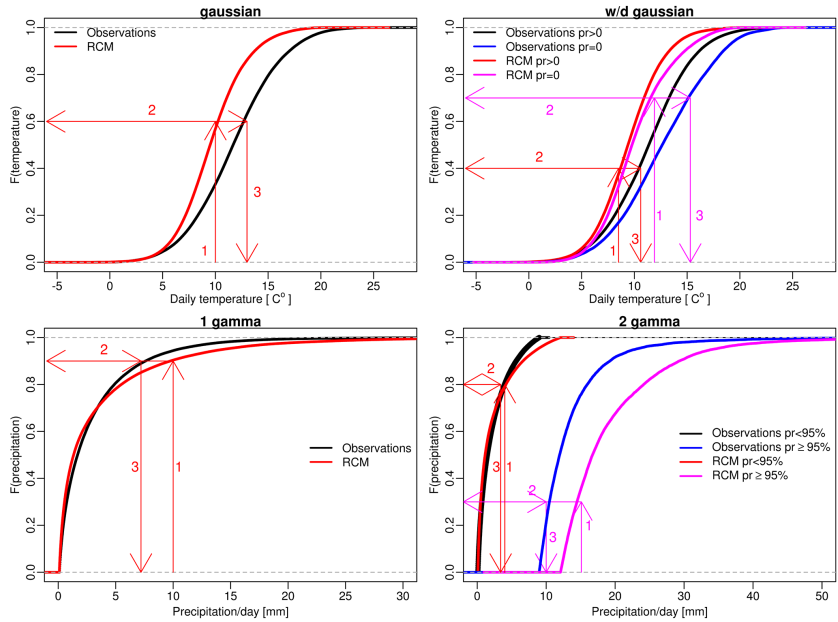

Figure 3. Procedure of the distribution based mapping. Upper panels for temperature adjustment and lower panels for precipitation (pr) adjustment. For temperature, Gaussian adjustment without wet-dry state separation (left) and with wet-dry separation (right) is shown. For precipitation, gamma adjustment with single gamma (left) and double gamma divided at 95th percentile (right) is shown. (1) Locate the cumulative probability value of RCM simulated daily temperature/precipitation. (2) Locate the observed temperature/precipitation value corresponding the same cumulative probability value as in (1). (3) This value is used as corrected value for RCM simulation.

\subsection{Bias correction methods}

The distribution based scaling (DBS) method described, e.g., in Yang et al. (2010) and Teutschbein and Seibert (2012) was used to scale temperature and precipitation time series to better represent observed distributions. The correction procedures using cumulative distribution functions (CDFs) are shown in Fig. 3. In this study CDFs are constructed on a daily basis for temperature and for all days with certain months for precipitation. The method of maximum likelihood is used to estimate distribution parameters.

Temperature $(T)$ is described by a Gaussian (normal) distribution with daily mean $(\mu)$ and standard deviation $(\sigma)$. The DBS approach for temperature included four steps: (1) to take into account the dependence between precipitation and temperature, the temperature data were divided into wet and dry days resulting in two sets of parameters; $\left(\mu_{\mathrm{w}}, \sigma_{\mathrm{w}}\right)$ for wet days and $\left(\mu_{\mathrm{d}}, \sigma_{\mathrm{d}}\right)$ for dry days, hereafter referred to as $\left(\mu_{\mathrm{w}-\mathrm{d}}, \sigma_{\mathrm{w}-\mathrm{d}}\right)$. The separation was conducted after excessive drizzle days were removed (described below; Eqs. 5, 6). In this study we also use the distribution parameters without wet-dry state separation $(\mu, \sigma)$. (2) To take into account seasonal variations, daily mean and standard deviation were calculated using a 15-day moving window and (3) were further smoothed with Fourier series with five harmonics on a daily basis over the control period 1961-2000, as in Yang et al. (2010). (4) These smoothed daily mean and standard 
deviation for each grid point were then used to calculate the daily $(d) \mathrm{CDFs}$ for observations $\left(\mu_{\mathrm{obs}}, \sigma_{\mathrm{obs}}\right)$ and RCMs $\left(\mu_{\text {contr }}, \sigma_{\text {contr }}\right)$ for the control period (Fig. 3). DBS parameters for the control period were used also to adjust the scenario (scen) runs. DBS procedure expressed in terms of the Gaussian CDF without wet-dry separation:

$$
\begin{aligned}
& T_{\text {contr }}(d)=F^{-1}\left(F\left(T_{\text {contr }}(d) \mid \mu_{\text {contr }}, \sigma_{\text {contr }}^{2}\right) \mid \mu_{\mathrm{obs}}, \sigma_{\mathrm{obs}}^{2}\right), \\
& T_{\text {scen }}(d)=F^{-1}\left(F\left(T_{\text {scen }}(d) \mid \mu_{\text {contr }}, \sigma_{\text {contr }}^{2}\right) \mid \mu_{\text {obs }}, \sigma_{\text {obs }}^{2}\right) .
\end{aligned}
$$

DBS procedure expressed in terms of Gaussian CDF with wet-dry separation:

$$
\begin{aligned}
& T_{\text {contr, w-d }}(d)=F^{-1} \\
& \cdot\left(F\left(T_{\text {contr, w-d }}(d) \mid \mu_{\text {contr, w-d }}, \sigma_{\text {contr, w-d }}^{2}\right) \mid \mu_{\text {obs, w-d }}, \sigma_{\text {obs, w-d }}^{2}\right), \\
& T_{\text {scen, w-d }}(d)=F^{-1} \\
& \cdot\left(F\left(T_{\text {scen, w-d }}(d) \mid \mu_{\text {contr, w-d }}, \sigma_{\text {contr, w-d }}^{2}\right) \mid \mu_{\text {obs, w-d }}, \sigma_{\text {obs, w-d }}^{2}\right) .
\end{aligned}
$$

For precipitation $(P)$ single and double gamma distributions were used in four steps. In contrast to Yang et al. (2010) where the DBS parameters (shape $\alpha$ and scale $\beta$ ) were estimated seasonally, we estimated DBS parameters on a monthly basis. Single CDF for certain month is used for the whole time slice (1961-2000). Also seasonally optimized parameters were tried out, but these produced too high monthly precipitation sums for Finland (not shown) and thus were not used. (1) For both distributions, excessive drizzle days in the RCM data were first removed by defining a cut-off value $\left(P_{\mathrm{th}, \mathrm{contr}, m}\right)$ that reduced the percentage of wet days in the RCMs to that of the observations on a monthly $(m)$ basis. In this study only days with observed precipitation larger than $0.1 \mathrm{~mm}\left(P_{\mathrm{th}, \mathrm{obs}, m}\right)$ were considered wet days, and the rest dry days. A monthly precipitation threshold value for each RCM control run $\left(P_{\text {th,contr, } m}\right)$ was then set to the cut-off value so that the percentage of RCM simulated and observed wet days matched (Eq. 5). Due to the stationary assumption the same threshold value was used to reduce the drizzle days for a future period to enable the scenario run to have different wet day frequency than the control run (Eq. 6). Precipitation amounts smaller than the threshold value were not redistributed to the remaining wet days.

$$
\begin{aligned}
& P_{\text {contr }}(d)= \begin{cases}0, & \text { if } P_{\text {contr }}(d)<P_{\mathrm{th}, \text { contr }, m} \\
P_{\text {contr }}, & \text { otherwise }\end{cases} \\
& P_{\text {scen }}(d)= \begin{cases}0, & \text { if } P_{\text {scen }}(d)<P_{\text {th }, \text { contr }, m} \\
P_{\text {scen }}, & \text { otherwise }\end{cases}
\end{aligned}
$$

(2) The remaining daily precipitation was adjusted to match the observed frequency distribution using single gamma distribution (Eq. 7). (3) To better capture the extreme precipitation events a double gamma distribution was also used, then the observed and RCM generated precipitation distributions were separated into two by the 95th percentile of
CDF ( $\left.P_{\text {obs,95th }}, P_{\text {contr,95th }}\right)$, resulting into two sets of parameters: $\left(\alpha_{1}, \beta_{1}\right)$ for below the 95 th percentile precipitation and $\left(\alpha_{2}, \beta_{2}\right)$ above it. (4) These monthly parameters for each grid point were then used to calculate the CDFs for observations $\left(\alpha_{\text {obs }}, \beta_{\text {obs }}\right)$ and RCMs $\left(\alpha_{\text {contr }}, \beta_{\text {contr }}\right)$ during the control period (Eqs. 9, 10; Fig. 3). Monthly DBS parameters for the control period and the 95 th percentile threshold $\left(P_{\text {contr,95th }}\right)$ were also used for the scenario (scen) runs (Eqs. 8, 11, 12). The DBS procedure expressed in terms of single gamma CDF:

$$
\begin{aligned}
& P_{\text {contr }}(d)=F^{-1} \\
& \quad \cdot\left(F\left(P_{\text {contr }}(d) \mid \alpha_{\text {contr }, m}, \beta_{\mathrm{contr}, m}\right) \mid \alpha_{\mathrm{obs}, m}, \beta_{\mathrm{obs}, m}\right), \\
& P_{\mathrm{scen}}(d)=F^{-1} \\
& \cdot\left(F\left(P_{\mathrm{scen}}(d) \mid \alpha_{\mathrm{contr}, m}, \beta_{\mathrm{contr}, m}\right) \mid \alpha_{\mathrm{obs}, m}, \beta_{\mathrm{obs}, m}\right),
\end{aligned}
$$

The DBS procedure expressed in terms of double gamma CDF:

$$
\begin{aligned}
& P_{\text {contr }, 1}(d)=F^{-1} \\
& \quad \cdot\left(F\left(P_{\mathrm{contr}}(d) \mid \alpha_{\mathrm{contr} 1, m}, \beta_{\mathrm{contr} 1, m}\right) \mid \alpha_{\mathrm{obs} 1, m}, \beta_{\mathrm{obs} 1, m}\right), \\
& \quad \text { if } P_{\mathrm{contr}}(d)<P_{\mathrm{contr}, 95 \mathrm{th}}(m), \\
& P_{\text {contr }, 2}(d)=F^{-1} \\
& \quad \cdot\left(F\left(P_{\mathrm{contr}}(d) \mid \alpha_{\mathrm{contr} 2, m}, \beta_{\mathrm{contr} 2, m}\right) \mid \alpha_{\mathrm{obs} 2, m}, \beta_{\mathrm{obs} 2, m}\right), \\
& \quad \text { if } P_{\mathrm{contr}}(d) \geq P_{\mathrm{contr}, 95 \mathrm{th}}(m), \\
& P_{\text {sken, } 1}(d)=F^{-1} \\
& \quad \cdot\left(F\left(P_{\mathrm{scen}}(d) \mid \alpha_{\mathrm{contr} 1, m}, \beta_{\mathrm{contr} 1, m}\right) \mid \alpha_{\mathrm{obs} 1, m}, \beta_{\mathrm{obs} 1, m}\right), \\
& \quad \text { if } P_{\mathrm{scen}}(d)<P_{\mathrm{contr}, 95 \mathrm{th}}(m), \\
& P_{\text {sken }, 2}(d)=F^{-1} \\
& \quad \cdot\left(F\left(P_{\mathrm{scen}}(d) \mid \alpha_{\mathrm{contr} 2, m}, \beta_{\mathrm{contr} 2, m}\right) \mid \alpha_{\mathrm{obs} 2, m}, \beta_{\mathrm{obs} 2, m}\right), \\
& \quad \text { if } P_{\text {scen }}(d) \geq P_{\mathrm{contr}, 95 \mathrm{th}}(m) .
\end{aligned}
$$

Wind speed and specific humidity of the RCM data were corrected by adding the monthly mean differences between the observations and the RCMs. The same corrections were used in the scenario periods. Since the wind speed and specific humidity affect only the calculation of lake evaporation in the hydrological model, it is assumed that this simple bias correction works sufficiently well to achieve corresponding water level and discharge distribution as with observed input variables.

\subsection{Hydrological model and modelling approaches}

The hydrological model used in this paper was from the watershed simulation and forecasting system (WSFS). It is a conceptual hydrological model developed and operated at Finnish Environment Institute (SYKE) (Vehviläinen et al., 2005). The WSFS is used as the national hydrological forecasting and flood warning system (Finnish Environment Institute, 2015) as well as for research purposes 
(e.g. Veijalainen et al., 2012; Jakkila et al., 2014; Huttunen et al., 2015). The conceptual rainfall-runoff model in the WSFS is based on the HBV (Hydrologiska Byråns Vattenbalansavdelning) model structure developed at SMHI (Bergström, 1976), but the models differ from each other, e.g., in the river routing, catchment description and in some process models such as the snow model (Vehviläinen, 1992; Vehviläinen et al., 2005). HBV-type models have been used in several climate change impacts studies in different parts of the world (e.g. Steele-Dunne et al., 2008; van Pelt et al., 2009), most commonly in Scandinavia (e.g. Andréasson et al., 2004; Beldring et al., 2008)

The WSFS hydrological model consists of small subbasins, numbering over 6000 in Finland with an average size of $60 \mathrm{~km}^{2}\left(20-500 \mathrm{~km}^{2}\right)$ (Vehviläinen et al., 2005). The water balance is simulated for each sub-basin, and sub-basin are connected to produce the water balance and simulate water storage and transfer in the river and lake network within the entire catchment. The sub-models in WSFS include a precipitation model calculating areal value and form for precipitation, a snow accumulation and melt model based on the temperature-index (degree-day) approach, a rainfall-runoff model with soil moisture, sub-surface and groundwater storages, and models for lake and river routing.

The WSFS was calibrated against water level, discharge and snow line water equivalent observations from 1981 to 2012. The Nash-Sutcliffe efficiency criterion $R^{2}$ (Nash and Sutcliffe, 1970) for the control period 1961-2000 in the four case study catchments was 0.78 for Loimijoki, 0.80 for Nilakka, 0.87 for Lentua and 0.87 for Ounasjoki. The $R^{2}$ values within the calibration period 1981-2000 are considerably better than in the validation period 1961-1980: 0.84 and 0.71 for Loimijoki, 0.91 and 0.68 for Nilakka, 0.92 and 0.81 for Lentua and 0.87 and 0.88 for Ounasjoki, respectively, for calibration and validation periods. The reasons for remarkably lower values in the validation period are the possible changes in rating curves in Loimijoki and Nilakka and the change of the rain station gauges from Wild to Tretjakov-type gauges. The measurement errors for different gauge types are done separately (Taskinen, 2015), but the uncertainty range of wind effect on snowfalls is much larger for Wild than Tretjakov.

\section{Results}

A distinct seasonal cycle can be seen in both temperature and precipitation in Finland (Fig. 4). Annual mean temperature varies from above $5{ }^{\circ} \mathrm{C}$ in southern Finland to below $-2{ }^{\circ} \mathrm{C}$ in northern Finland with maximum monthly mean temperatures in July (ca. $15^{\circ} \mathrm{C}$ ) and minimum in January-February (ca. $-12{ }^{\circ} \mathrm{C}$ ). The primary peak in seasonal precipitation accumulation occurs in summer (ca. $220 \mathrm{~mm} \mathrm{season}^{-1}$ ) and secondary in autumn (ca. $180 \mathrm{~mm} \mathrm{season}^{-1}$ ), spring being the driest season (ca. $110 \mathrm{~mm} \mathrm{season}^{-1}$ ). In this study we define
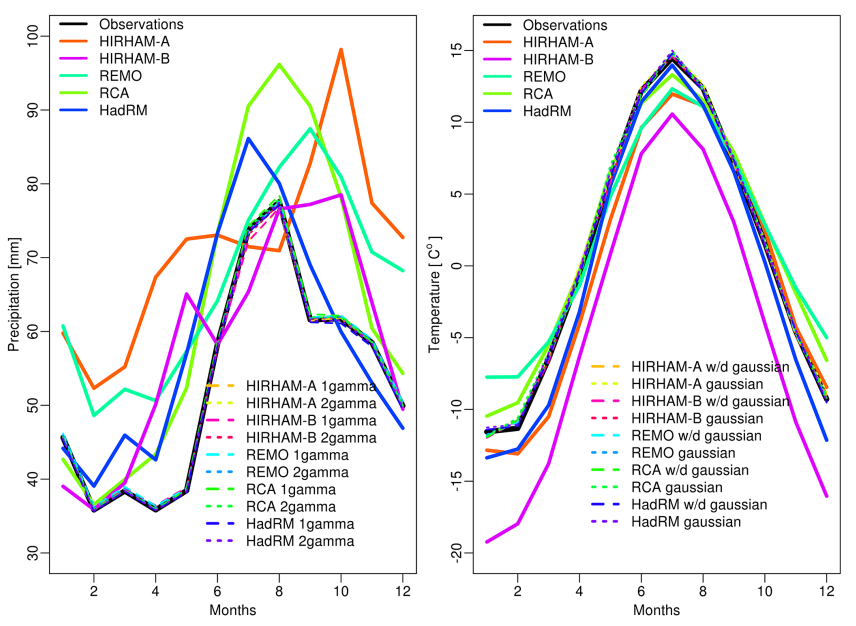

Figure 4. Monthly mean precipitation accumulation (left) and temperature (right) in observations and RCMs in Finland during the control period 1961-2000. Observations (black) and uncorrected RCMs (colours) in solid lines, adjusted RCMs in dashed and dotted lines. Monthly mean precipitation adjusted with single gamma (1gamma) are presented as dashed lines, and with double gamma (2gamma) as dotted lines (left panel). Monthly mean temperatures adjusted with wet-dry state separation (w-d Gaussian) are presented as dashed lines and without wet-dry separation (Gaussian) as dotted lines (right panel). All adjusted values follow closely the observations and no big differences can be seen between the two bias correction procedures.

torrential precipitation to be daily precipitation accumulation exceeding $20 \mathrm{~mm} \mathrm{day}^{-1}$ which is the official threshold value used in FMI.

\subsection{RCM temperature and precipitation in control period}

The five RCMs used in this study are able to capture the annual cycle of temperature in the control period quite well, but monthly temperatures are commonly underestimated throughout the year except in winter by RCA and REMO and in autumn by HIRHAM-A (Fig. 4). The CDFs show that all RCMs cumulate too much below $0^{\circ} \mathrm{C}$ temperatures and too little above $0^{\circ} \mathrm{C}$ temperatures especially in spring, although also in winter and autumn (Fig. 5).

There are prominent differences in the ability of RCMs to capture the annual cycle of precipitation during the control period (Fig. 4). All models in this study heavily overestimate precipitation accumulation almost throughout the year with some exceptions in summer and winter. In particular, HIRHAM-A and HIRHAM-B produce too much precipitation in spring and autumn and are too dry in summer. The overestimation in accumulated precipitation is relatively largest in spring, varying from $2.6-61 \%$ in Nilakka to $24-81 \%$ in Ounasjoki (Table 2). All RCMs show a higher percentage of wet days than observed, which is caused by 

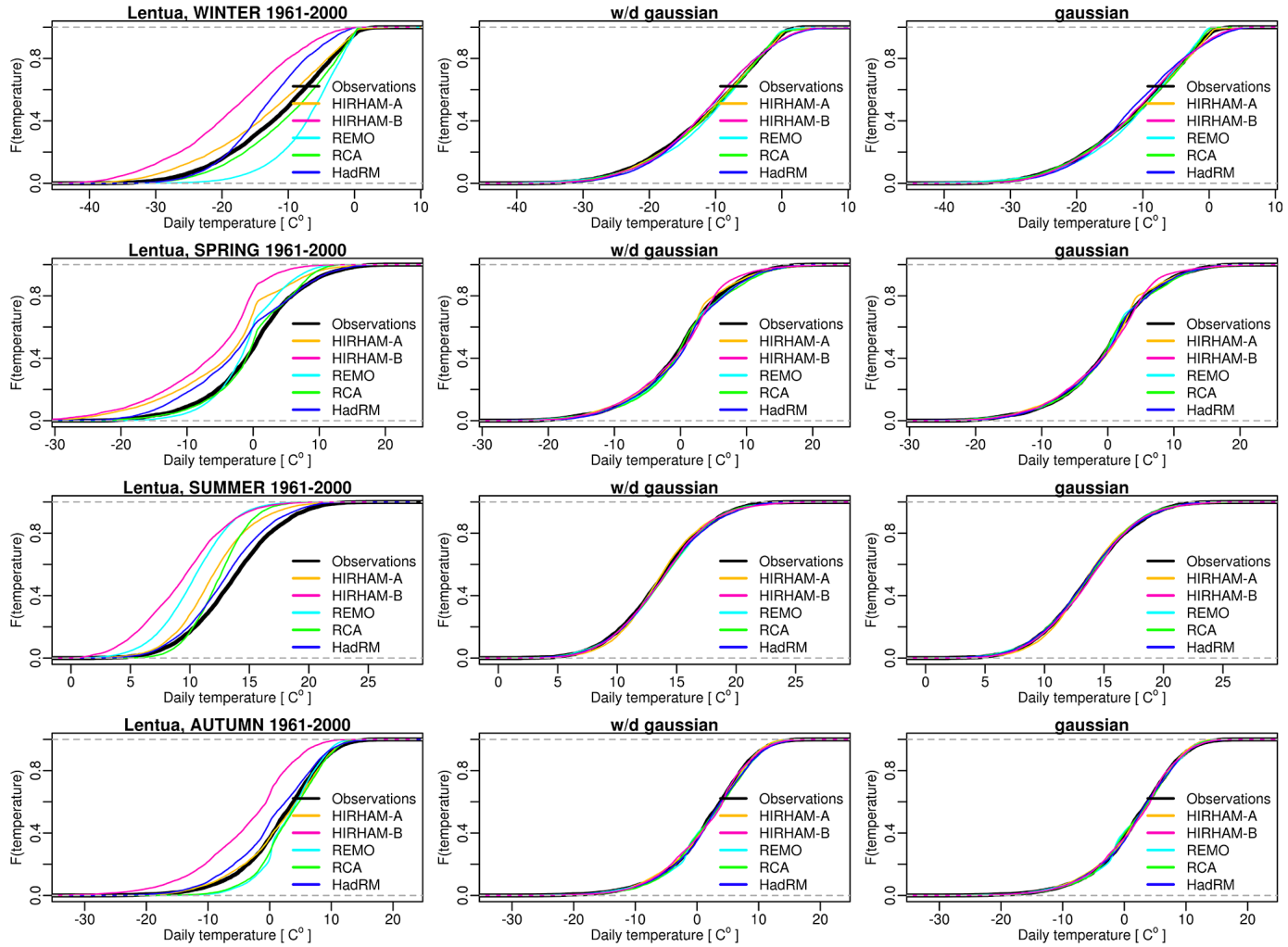

Figure 5. Cumulative distribution functions for daily temperature in Lentua catchment during the control period 1961-2000. Observations and uncorrected RCM data in left column, daily RCM temperatures adjusted with wet-dry state separation (w-d Gaussian) are presented in middle column and without wet-dry separation (Gaussian) in right column. Winter is shown in first row, spring in second row, summer in third row and autumn in bottom row. All the adjusted values closely follow the observed distribution and no big differences can be seen between the two bias correction procedures.

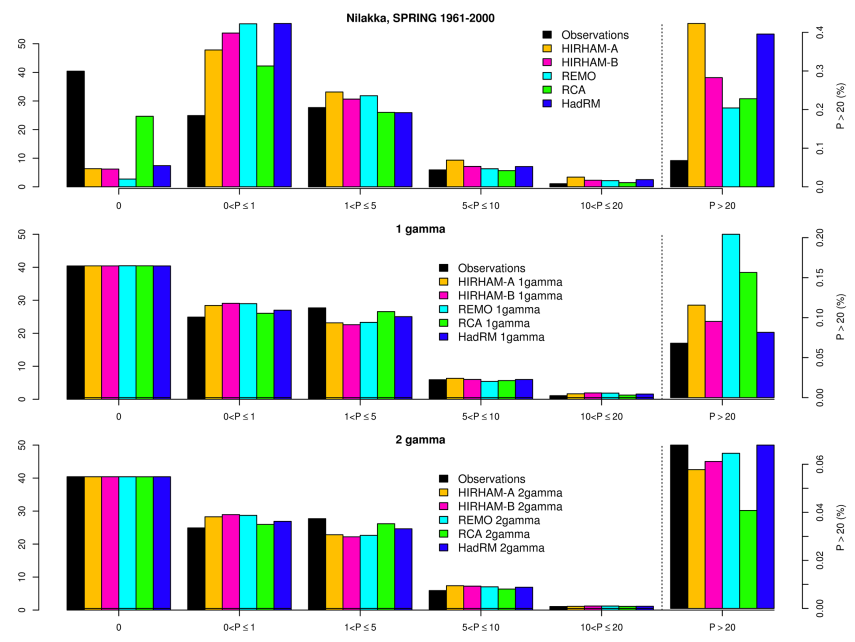

Figure 6. Distribution of daily precipitation amounts during the control period 1961-2000 spring in Nilakka catchment in observations and uncorrected RCM data (top panel), single Gammaadjusted RCM data (middle panel) and double Gamma-adjusted RCM data (bottom panel). Notice the uneven precipitation division and different scaling for precipitation amounts greater than $20 \mathrm{~mm}$ day $^{-1}$. too high percentage of light precipitation $\left(\leq 1 \mathrm{mmday}^{-1}\right.$; Fig. 6). Occurrence of torrential $\left(>20 \mathrm{~mm} \mathrm{day}^{-1}\right)$ precipitation events is overestimated in RCMs in every catchment and season.

After applying the DBS method, biases in seasonally calculated daily mean temperatures in uncorrected RCM data are significantly reduced (Figs. 4, 5), from $-8.7-5.3$ to $-0.2-0.5^{\circ} \mathrm{C}$. Also the standard deviation of the DBSadjusted values is closer to observed values than that of uncorrected RCM data (not shown). DBS scaling preserves the $\mathrm{RCM}$ temperature variability in CDFs. The strong temperature increase around $0^{\circ} \mathrm{C}$ found in the uncorrected $\mathrm{RCM}$ data is reduced after DBS scaling but can still be found from the CDFs (Fig. 5), although shifted towards observed values and higher temperatures. Daily temperatures adjusted with wet-dry separation produce more frequently higher winter maxima $\left(>5^{\circ} \mathrm{C}\right)$ and lower minima $\left(<-30^{\circ} \mathrm{C}\right)$ than adjustment without the separation (Fig. 7). These extrema are originated from the separation of days to dry and wet which especially affects the CDF of dry days due to the small number of days (approx. 7-16 days month ${ }^{-1}$ ) available. Otherwise there are no distinct differences between the two DBS approaches (Figs. 4, 5,7), both give distributions that are similar to the 
Table 2. Deviation between observed and RCM accumulated seasonal precipitation during control period 1961-2000 in uncorrected and DBS-adjusted (single gamma is 1 gamma, double gamma is 2 gamma) precipitation in percent. Values are shown for Loimijoki in southern Finland and Ounasjoki in northern Finland to demonstrate the spatial variation.

\begin{tabular}{|c|c|c|c|c|c|c|c|}
\hline & & Uncorrected & $1 \mathrm{Gamma}$ & 2 Gamma & Uncorrected & 1 Gamma & 2 Gamma \\
\hline & & & Loimijoki & & & Ounasjoki & \\
\hline \multirow{5}{*}{ 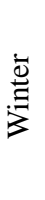 } & HIRHAM-A & 53.04 & 0.23 & -0.05 & 45.27 & -0.53 & -0.55 \\
\hline & REMO & 12.22 & 0.52 & 0.19 & 34.55 & 0.04 & -0.26 \\
\hline & RCA & 5.42 & 0.04 & -0.18 & 5.93 & -0.59 & -0.57 \\
\hline & HadRM & -0.62 & -0.76 & -0.46 & 12.37 & -1.49 & -0.88 \\
\hline & HIRHAM-B & 2.11 & -0.69 & -0.65 & -3.85 & -0.86 & -0.53 \\
\hline \multirow{5}{*}{$\begin{array}{l}\stackrel{\infty}{\Xi} \\
\text { ڤn } \\
\text { ڤn }\end{array}$} & HIRHAM-A & 77.04 & 0.73 & 0.39 & 80.50 & 1.58 & 0.74 \\
\hline & REMO & 29.71 & 1.04 & 0.59 & 54.51 & 1.58 & 0.73 \\
\hline & RCA & 30.91 & 0.47 & 0.26 & 23.75 & 0.44 & 0.16 \\
\hline & HadRM & 42.41 & 0.22 & 0.15 & 35.76 & -0.55 & -0.23 \\
\hline & HIRHAM-B & 40.80 & 0.93 & 0.57 & 39.34 & 1.31 & 0.64 \\
\hline \multirow{5}{*}{$\begin{array}{l}\dot{\Phi} \\
\Xi \\
\Xi \\
\Xi\end{array}$} & HIRHAM-A & -21.75 & -2.72 & -1.26 & 16.81 & -1.16 & -0.46 \\
\hline & REMO & 2.90 & -0.09 & 0.03 & 16.44 & 0.15 & 0.09 \\
\hline & $\mathrm{RCA}$ & 27.19 & 1.29 & 0.56 & 17.31 & 0.51 & 0.23 \\
\hline & HadRM & 1.27 & -0.15 & -0.03 & 26.88 & -0.67 & -0.20 \\
\hline & HIRHAM-B & -20.53 & -1.47 & -0.63 & -1.38 & -1.47 & -0.60 \\
\hline \multirow{5}{*}{$\begin{array}{l}\text { 䒠 } \\
\stackrel{\Xi}{\Xi}\end{array}$} & HIRHAM-A & 24.27 & -0.54 & 0.01 & 55.70 & 0.59 & 0.49 \\
\hline & REMO & 6.65 & 0.35 & 0.42 & 41.47 & 1.08 & 0.78 \\
\hline & $\mathrm{RCA}$ & 22.94 & 0.91 & 0.68 & 34.23 & 1.22 & 0.72 \\
\hline & HadRM & -10.56 & -0.61 & -0.12 & 18.65 & -0.53 & 0.06 \\
\hline & HIRHAM-B & 17.17 & 0.87 & 0.85 & 21.96 & 0.26 & 0.31 \\
\hline
\end{tabular}

observations. Due to the cases where daily winter maxima were excessively too high (e.g. $>15^{\circ} \mathrm{C}$ in January) in DBS with wet-dry state separated data, we decided to use the DBS method without separation in further analysis of hydrological simulations.

Both single and double gamma DBS approaches for precipitation are able to reduce biases in seasonal precipitation accumulation from $-22-81$ to $-3.0-1.7 \%$ (Figs. 4, 6; Table 2) in all catchments. Distribution of drizzle and torrential precipitation is shifted towards observations and the number of dry days is forced to match observed values (Fig. 6).

There are no considerable differences in monthly mean accumulated precipitation between single and double gamma DBS. The largest differences are found in the treatment of heavy ( $>$ 95th percentile of CDF) precipitation (Figs. 6, 8). Considering daily mean precipitation amounts in the heavy precipitation distribution, DBS with double gamma overestimates daily mean heavy precipitation amounts in July by $0.2-6.5 \%$ and DBS with single gamma by $12.0-21.7 \%$ in Loimijoki and in Ounasjoki by $-0.3-1.3$ and by $3.4-14.8 \%$, respectively, compared to observed values. Due to a longer tail in the single gamma distribution in the heavy precipitation end of the distribution, the high values are in many cases larger and more frequent with single gamma than with double gamma DBS. In some cases the single gamma DBS approach even increases heavy precipitation values compared to ob- served values. Nevertheless, single gamma distribution was slightly better than double gamma, e.g., in winter and spring in northern Finland (root mean square error (RMSE) 2.783.10 in single gamma and 3.07-3.10 in double gamma in January in Ounasjoki). Still, in most cases the double gamma distribution produces heavy precipitation values closer to observed values than single gamma.

\subsection{RCM temperature and precipitation in the future}

Finland is expected to experience a warmer and wetter climate towards the end of this century. Future changes in seasonal precipitation and mean temperature in Loimijoki catchment are shown in Table 3. After DBS adjustment, seasonal temperature increase varies from 1.4 to $5.1^{\circ} \mathrm{C}$ in Loimijoki and from 1.3 to $6.6^{\circ} \mathrm{C}$ in Ounasjoki in the latter part of this century, being the largest in winter. As for the control period, the DBS approach with wet-dry day separation produces higher temperature maxima for the scenario period compared to DBS approach without separation. Thus, it also produces higher seasonal mean values than DBS scaling without wetdry separation. No distinct differences between the single and double gamma DBS approaches can be found for monthly and seasonal mean precipitation sums. Again, the greatest differences can be found from torrential precipitation, which are more frequent and intense in single gamma than in dou- 

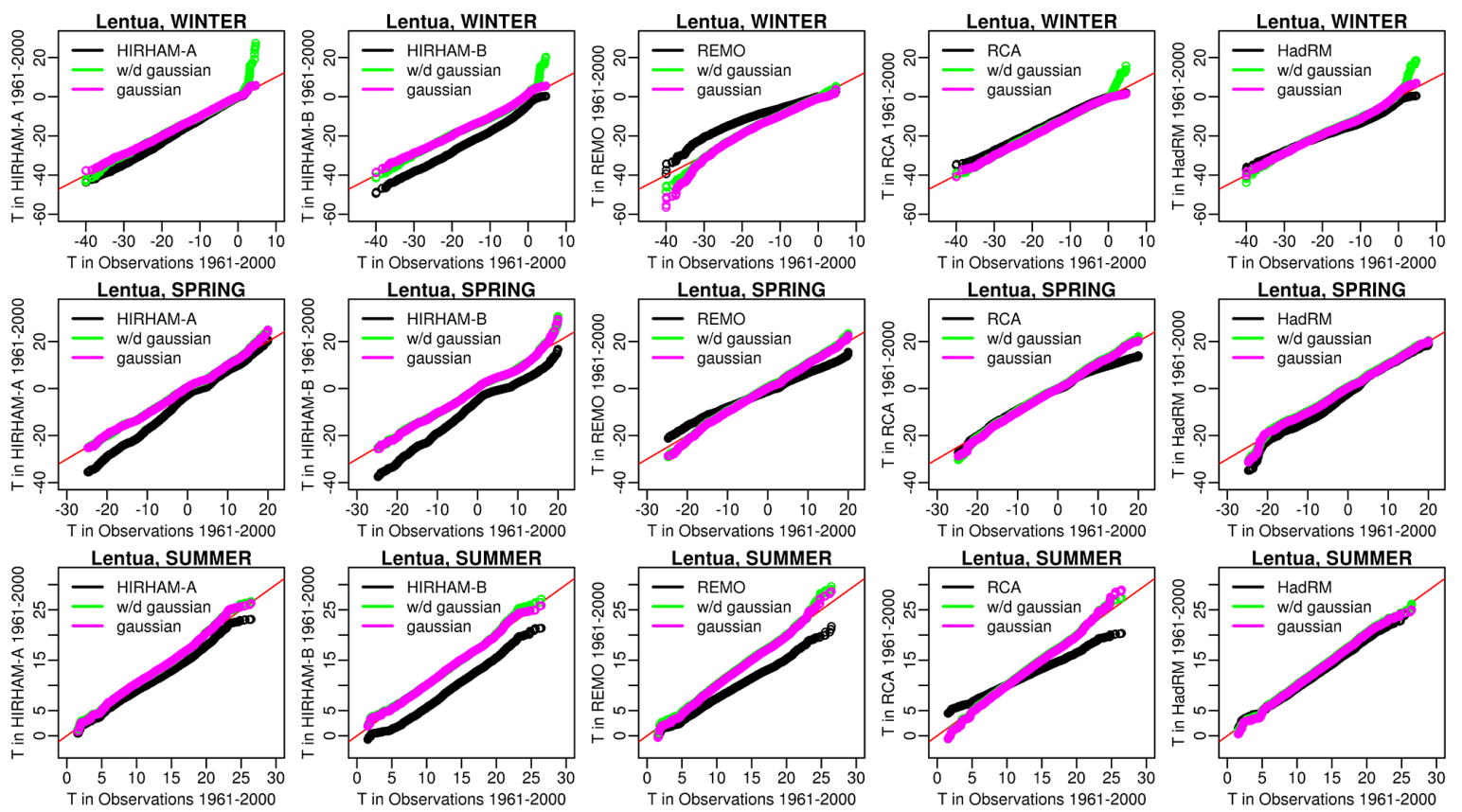

Lentua, SUMMER
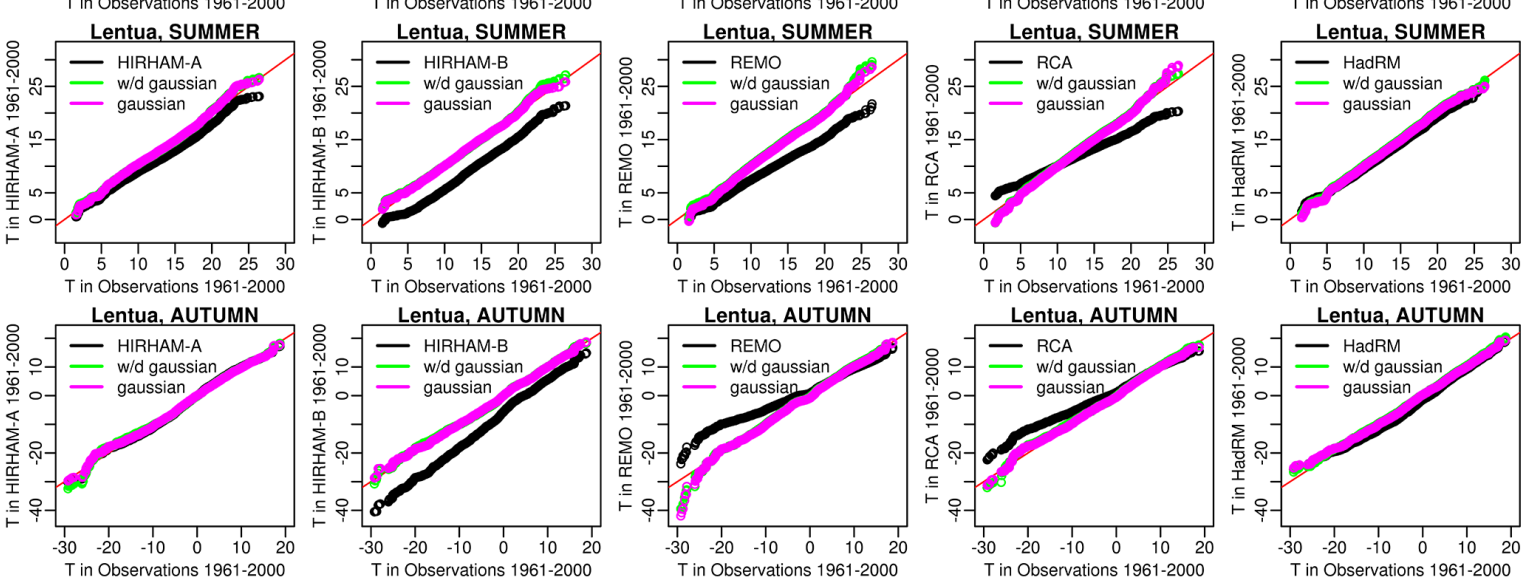

Figure 7. Comparison between uncorrected (black) and DBS-adjusted (pink without wet-dry state separation and green with wet-dry state separation) daily temperatures during control period 1961-2000 in Lentua. Red line corresponds to the observations.

ble gamma DBS-adjusted values. Future changes in seasonal precipitation sums vary more than temperature depending on RCM as well as season and area of investigation, and can even decrease by the end of this century. After DBS adjustment the change in seasonal precipitation sums varies from $1.7-39 \%$ in Nilakka to $-7.5-37.7 \%$ in Loimijoki by the end of this century, being largest in winter.

The DBS method preserves the temperature trend of the uncorrected RCM data during 1961-2100 relatively well (Table 4; Fig. 9). The projected temperature trends in uncorrected RCM data vary between 0.3 and $0.5^{\circ} \mathrm{Cdecade}^{-1}$ in the used scenarios. The differences between uncorrected RCM and DBS-adjusted seasonal trends are mainly less than $\pm 0.1^{\circ} \mathrm{Cdecade}^{-1}$ (Table 4). The largest differences between temperature trends in uncorrected and DBS-adjusted data can be seen in the scenarios of REMO and RCA, which produce more than $0.1{ }^{\circ} \mathrm{Cdecade}^{-1}$ larger temperature rise after DBS (Fig. 9). This is probably due to a too narrow temperature distribution (low standard deviation) in the control period compared to observed values (not shown). In the scenario period the standard deviation decreases even further, with increasing daily temperatures, causing more pronounced warming after DBS adjustment. Other climate models in this study do not produce any prominent decrease in standard deviation during the scenario period and thus the trends are better preserved.

Also trends in precipitation are preserved sufficiently well among RCMs after DBS adjustment and no distinct differences between RCMs or the two DBS methods can be found. In Loimijoki and Ounasjoki catchments most of the uncorrected scenarios show positive precipitation trends from 1.1 to $4.2 \mathrm{~mm} \mathrm{decade}^{-1}$ (Table 4). Only HIRHAM-A in Loimijoki and REMO in Ounasjoki do not show significant trends. The differences between RCM and adjusted seasonal trends are mainly from -0.6 to $+0.3 \mathrm{~mm} \mathrm{decade}^{-1}$ (Table 4). The largest differences between trends of uncorrected and DBS-adjusted RCM data can be seen in seasonal precipitation simulated by HadRM in Ounasjoki (from -1.9 to $-1.6 \mathrm{~mm} \mathrm{decade}^{-1}$ ) (Fig. 10). The trend simulated by HIRHAM-B is largest in spring in all catchments, which causes the large increase in precipitation accumulation (Table 3). Even though the trends are largest in winter or spring, the summer and autumn remain the wettest seasons of the year. 
Table 3. Changes in uncorrected and DBS-adjusted RCM seasonal precipitation sums in $\%$ and daily mean temperatures as ${ }^{\circ} \mathrm{C}$ between control (1961-2000) and scenario periods (2051-2090). Values are shown for winter and spring in Loimijoki catchment in southern Finland.

\begin{tabular}{|c|c|c|c|c|c|c|c|}
\hline & & \multicolumn{3}{|c|}{ Precipitation $(\%)$} & \multicolumn{2}{|c|}{ Temperature $\left({ }^{\circ} \mathrm{C}\right)$} & \multirow[b]{2}{*}{ Gaussian } \\
\hline & & Uncorrected & $1 \mathrm{Gamma}$ & 2 Gamma & Uncorrected & W-D Gaussian & \\
\hline \multirow{5}{*}{ 离 } & HIRHAM-A & 11.0 & 12.3 & 11.2 & 2.9 & 3.0 & 2.7 \\
\hline & REMO & 12.7 & 15.7 & 13.9 & 3.4 & 5.1 & 4.5 \\
\hline & RCA & 19.0 & 21.0 & 19.7 & 3.6 & 4.7 & 4.2 \\
\hline & HadRM & 9.3 & 8.9 & 8.6 & 4.4 & 5.0 & 4.5 \\
\hline & HIRHAM-B & 23.6 & 25.4 & 26.2 & 4.9 & 4.3 & 3.8 \\
\hline \multirow{5}{*}{ 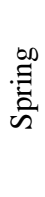 } & HIRHAM-A & -4.6 & -4.0 & -4.6 & 2.7 & 2.6 & 2.5 \\
\hline & REMO & 9.2 & 13.2 & 11.7 & 2.8 & 3.4 & 3.3 \\
\hline & RCA & 16.7 & 17.1 & 17.8 & 2.7 & 3.8 & 3.6 \\
\hline & HadRM & 6.7 & 7.3 & 6.1 & 4.5 & 4.3 & 4.1 \\
\hline & HIRHAM-B & 27.1 & 37.7 & 34.2 & 3.8 & 3.5 & 3.4 \\
\hline \multirow{5}{*}{$\begin{array}{c}\bar{\Xi} \\
\Xi \\
\Xi \\
\text { ڤ }\end{array}$} & HIRHAM-A & -6.8 & -7.5 & -6.7 & 2.1 & 2.4 & 2.4 \\
\hline & REMO & 13.7 & 14.0 & 13.6 & 2.3 & 2.9 & 2.7 \\
\hline & RCA & 11.4 & 13.9 & 13.3 & 2.0 & 3.3 & 3.2 \\
\hline & HadRM & 8.9 & 7.5 & 7.5 & 4.0 & 4.3 & 4.2 \\
\hline & HIRHAM-B & 17.0 & 16.4 & 15.9 & 1.4 & 1.4 & 1.5 \\
\hline \multirow{5}{*}{ 声 } & HIRHAM-A & 1.0 & 0.4 & -0.5 & 1.4 & 1.4 & 1.4 \\
\hline & REMO & 11.2 & 11.8 & 10.4 & 2.8 & 3.9 & 3.6 \\
\hline & RCA & 11.7 & 13.4 & 11.9 & 2.8 & 3.8 & 3.5 \\
\hline & HadRM & 4.5 & 4.5 & 3.7 & 4.2 & 4.3 & 4.0 \\
\hline & HIRHAM-B & 6.4 & 7.3 & 7.0 & 3.0 & 2.7 & 2.5 \\
\hline
\end{tabular}

\subsection{Impact of bias correction on simulated hydrology}

The discharges simulated with uncorrected RCM values (Fig. 11) show large differences compared to the observed discharges and discharges simulated with observed meteorological input values in the control period (hereinafter referred to as "control simulation"). The differences in simulated mean discharges in the control simulation and using RCM data with and without DBS adjustment for Loimijoki and Ounasjoki test sites are shown in Table 3. In the four test sites the annual mean discharges simulated with uncorrected RCM inputs were 16-104\% larger than annual mean discharges of the control simulation. The higher annual mean discharges are mainly caused by overestimation of precipitation in RCMs.

The seasonal differences are more pronouncedly affected by temperature biases in the RCM data. The HadRM and HIRHAM-B have negative temperature biases during winter, which cause smaller winter discharges in southern and central Finland. The negative temperature biases in spring (HIRHAM-B) cause a delay in the spring flood peak (Fig. 11). This delay causes negative biases to mean spring discharges in northern Finland even though the snowmelt floods are larger due to greater snow accumulation caused by positive precipitation and negative temperature biases. Summer mean discharges become larger with all uncorrected
RCM outputs due to positive precipitation biases and larger recession flows caused by greater and delayed spring floods.

Using single gamma or double gamma precipitation corrections and temperature corrections without wet-dry separation, the biases in simulated mean discharges can be effectively reduced (Table 5). The differences in annual mean discharges decreased to less than $12 \%$ in all test sites with DBS-adjusted RCM outputs. The difference is at the same level as the difference between control simulation discharges and observed discharges (less than 13\%), which indicates that biases in annual mean discharges are partly explained by the model sensitivity on input variables and partly by the residual biases in corrected RCM outputs.

The differences in seasonal mean discharges between simulations with DBS-adjusted RCM data and control simulation are in many cases larger than differences between observed discharges and discharges in the control simulation. Differences larger than $30 \%$ are only found in winter and summer, when the discharges are low. But the remaining biases larger than $20 \%$ during high flow season in Loimijoki found in REMO and RCA and larger than $50 \%$ during the low flow season in HadRM and HIRHAM-B may have significant effect on the seasonal changes and changes in extreme discharges in climate change projections. The main reason for large and in some cases even larger remaining biases in winter discharges than in uncorrected data is the sensitivity of the hydrological model on near-zero temperatures. 

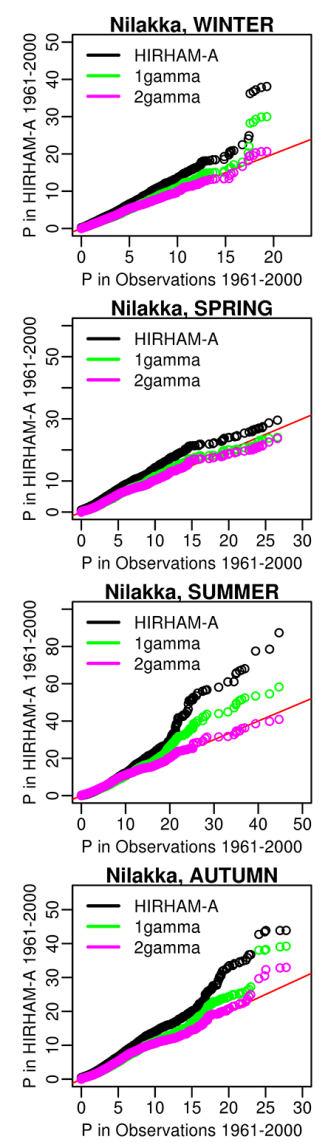

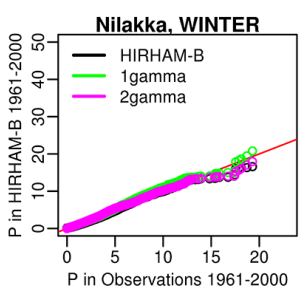

Nilakka, SPRING
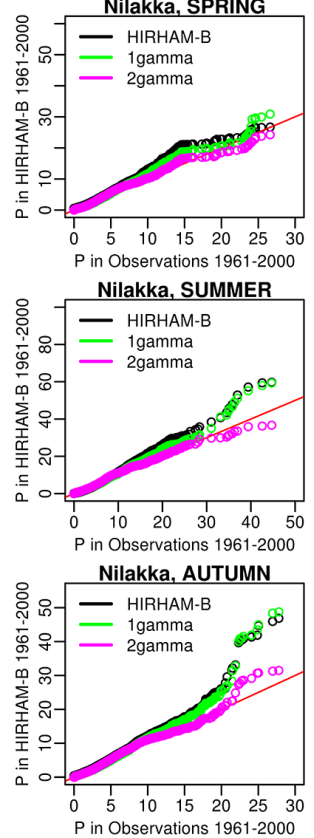

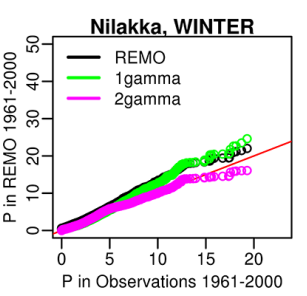

Nilakka, SPRING
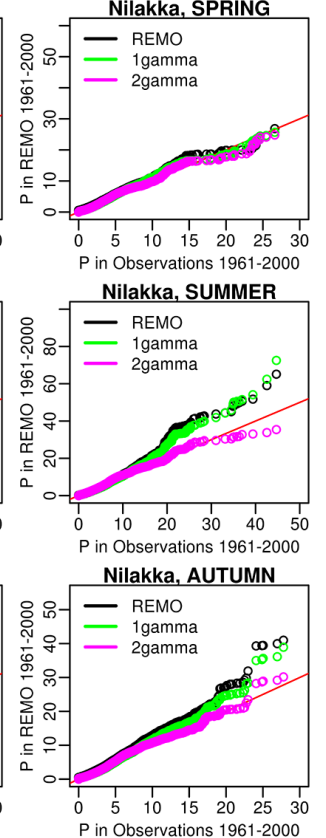

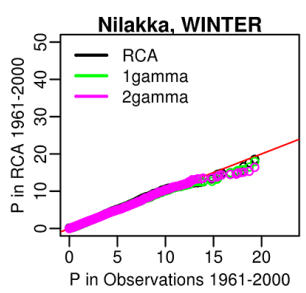

Nilakka, SPRING
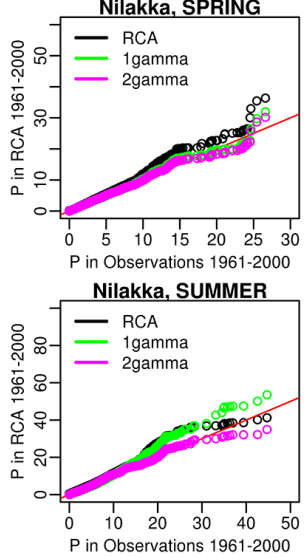

Nilakka, AUTUMN

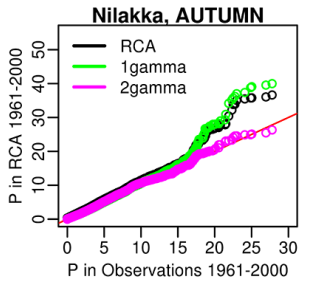

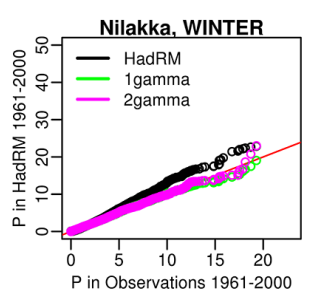

Nilakka, SPRING

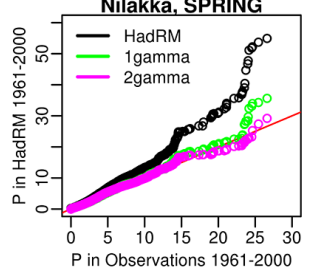

Nilakka, SUMMER

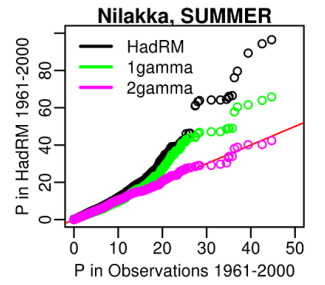

Nilakka, AUTUMN

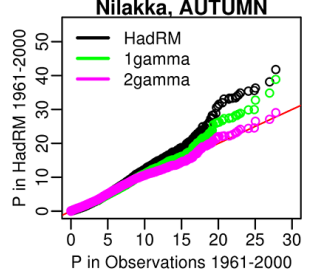

Figure 8. Comparison between uncorrected (black) and DBS-adjusted daily precipitation (single gamma in green and double gamma in pink) during control period 1961-2000 in Nilakka. Red line corresponds to the observations.

Even though the DBS method corrects the mean temperatures efficiently close to observations, the remaining biases in winter temperature extremes, which in control period are slightly above zero, cause remarkable biases in winter discharges and snow accumulation in the hydrological simulation. However, the seasonal variations in mean discharges after the DBS adjustment are remarkably closer to variations of control simulation (Fig. 11), highlighting the fact that the bias correction is required for RCM data used in studies of climate change effects on hydrology.

In addition to biases in RCM temperature and precipitation data, the biases in wind speed (WS) and specific humidity (SH) also affect the WSFS discharge simulations for catchments with high lake percentages. Biases in WS and SH of RCMs affect the lake evaporation in the hydrological model and typically cause a 5-45\% bias in the annual lake evaporation sums. In most of the study catchments the bias is largest in the RCA scenario giving 25-35\% negative bias caused by positive bias of SH and negative bias of WS. The bias in lake evaporation can be effectively decreased to $0-13 \%$ by the simple mean bias correction method (Fig. 12).

The uncorrected WS and SH of RCMs cause a 0-11\% bias in annual mean discharges, and a $0-20 \%$ bias in au- tumn mean discharges in the outlet of Nilakka, which has the highest lake percentage of the study catchments $(18 \%)$. In the catchments of Loimijoki and Lentua the biases in mean discharges (0-2 and 0-4\%) and autumn discharges (0-7 and $0-8 \%$ ) are smaller, and in the most northern located catchment of Ounasjoki the bias is insignificant.

The effect of different correction methods on annual and seasonal discharges as well as on the changes in discharges by the 2051-2090 period are shown in Fig. 13. The deviations of the simulated discharges with RCM data compared to control simulations in four test sites using all five scenarios without corrections, only with temperature corrections, precipitation corrections and with both temperature and precipitation corrections are shown in the upper part of the box plot. The lower figure shows the results of the climate change impacts on mean discharges with different corrections. The results show that the effect of precipitation correction affects more the annual discharges and the temperature correction affects more the seasonal discharges. However, without temperature correction the annual discharges still have positive biases due to cold biases, which decrease evapotranspiration. All four combinations of DBS temperature and precipitation correction methods used in this study produce similar results 

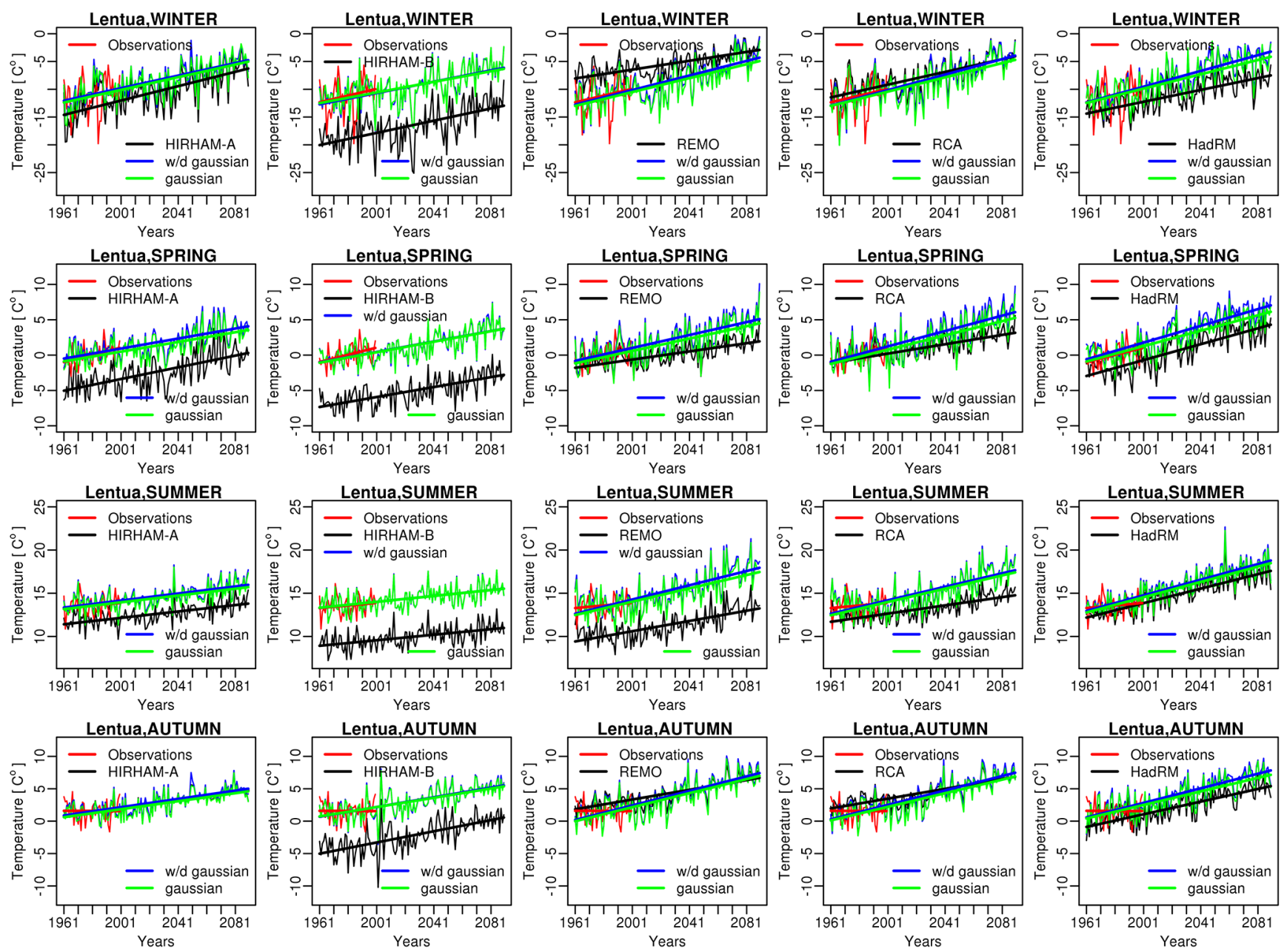

Figure 9. Seasonal trends in observed (red, 1961-2000) and RCM simulated daily temperatures in Lentua basin during 1961-2090. Uncorrected RCM daily temperatures in black, temperatures adjusted with wet-dry separation in blue and without wet-dry separation in green.

and none of the different DBS approaches are found to be superior with respect to mean discharges. Thus, the selection of the best methods is based on the performance of the correction method in decreasing the extreme temperature and precipitation biases, in which the temperature correction without wet-dry separation and double gamma for precipitation work significantly better.

Because of the biases in uncorrected RCM data, the mean discharge peaks caused by snowmelt (Fig. 11) are significantly larger than the control simulation discharge peaks, and the seasonal variation of discharges is also altered. Without effective bias correction the results of climate change impact studies could easily lead to false conclusions. The effect of DBS adjustment on changes in seasonal mean discharges is more pronounced than on annual discharges, because the temperature biases of uncorrected data have significant influence on seasonal discharges. The changes in mean winter and spring discharges may be 2 or even 3 times larger than without temperature correction (Fig. 13). If only temperature bias is corrected, the relative changes are close to the changes in temperature and precipitation corrected data, but the absolute changes are much larger due to wet bias in RCM data.

The temperature correction is essential especially when the high and low flows are studied. The difference between the changes in mean high discharges (MHQ) and mean low discharges (MNQ) by using uncorrected RCM data can be even to the other direction when the uncorrected RCM data are used compared to changes in the DBS-adjusted data. This can also be seen in summer mean discharges with HIRHAMB scenario. The uncorrected scenario shows $35 \%$ decrease in summer discharges in Loimijoki due to large recession flow after spring flood in the control period, which caused over $300 \%$ wet bias in mean summer discharges (Tables 5 , 6). The DBS-adjusted data of HIRHAM-B show a slight increase in summer discharges because a large precipitation increase compensates the increased evapotranspiration in this scenario. 
Table 4. Trends in seasonal precipitation sum $\left(\mathrm{mmdecade}^{-1}\right)$ and temperature $\left({ }^{\circ} \mathrm{C}\right.$ decade $\left.^{-1}\right)$ in uncorrected and DBS-adjusted $\mathrm{RCM}$ simulations. Values are shown for spring in Loimijoki and Ounasjoki to demonstrate the spatial variation.

\begin{tabular}{|c|c|c|c|c|c|}
\hline \multicolumn{3}{|c|}{ Precipitation $\left(\mathrm{mm} \mathrm{decade}^{-1}\right)$} & \multicolumn{3}{|c|}{ Temperature $\left({ }^{\circ} \mathrm{C}\right.$ decade $\left.{ }^{-1}\right)$} \\
\hline Spring & Loimijoki & Ounasjoki & Spring & Loimijoki & Ounasjoki \\
\hline HIRHAM-A & -0.2 & 1.1 & HIRHAM-A & 0.3 & 0.5 \\
\hline 1 gamma & -0.1 & 1.3 & w-d Gaussian & 0.3 & 0.5 \\
\hline 2 gamma & -0.1 & 1.3 & Gaussian & 0.3 & 0.4 \\
\hline REMO & 1.4 & -0.1 & REMO & 0.3 & 0.4 \\
\hline 1 gamma & 1.6 & 0.1 & w-d Gaussian & 0.4 & 0.5 \\
\hline 2 gamma & 1.4 & 0.1 & Gaussian & 0.4 & 0.5 \\
\hline $\mathrm{RCA}$ & 2.3 & 1.5 & $\mathrm{RCA}$ & 0.3 & 0.3 \\
\hline 1 gamma & 1.8 & 1.2 & w-d Gaussian & 0.4 & 0.6 \\
\hline 2 gamma & 1.9 & 1.2 & Gaussian & 0.4 & 0.5 \\
\hline HadRM & 1.1 & 4.9 & HadRM & 0.5 & 0.5 \\
\hline 1 gamma & 0.8 & 3.3 & w-d Gaussian & 0.5 & 0.6 \\
\hline 2 gamma & 0.7 & 3.3 & Gaussian & 0.5 & 0.5 \\
\hline HIRHAM-B & 4.2 & 3.5 & HIRHAM-B & 0.4 & 0.4 \\
\hline 1 gamma & 4.7 & 3.5 & w-d Gaussian & 0.4 & 0.4 \\
\hline 2 gamma & 4.4 & 3.5 & Gaussian & 0.4 & 0.4 \\
\hline
\end{tabular}

The ability of the DBS method to preserve the precipitation and temperature trends (Figs. 9, 10) in most cases leads to similar changes in simulated annual mean discharges with uncorrected and DBS-adjusted RCM data (Fig. 13 and Table 6). In the HadRM-scenario, the DBS-adjusted data produce a lower increase than the uncorrected scenario in northern Finland, due to a smaller increase in precipitation trends after DBS adjustment. In northern Finland the differences between the results from simulations with uncorrected and DBS-adjusted data are clearest in spring, when the absolute biases in mean discharges in the control period are highest. The uncorrected HIRHAM-A and HIRHAM-B produce negative bias in mean spring discharges in the control period due to delayed spring floods. Thus, without bias corrections these scenarios produce too high increases in mean spring discharges.

\subsection{Future scenarios for discharges}

The results show that climate change will have a significant impacts on seasonality of discharges in Finland due to increasing precipitation and shorter wintertime, which influence snow accumulation and increase evapotranspiration (Fig. 14). The springtime snowmelt floods will occur earlier and the average wintertime discharges will increase because the temperature will rise more often above zero in winter increasing rainfall and causing occasional snowmelt. The summer discharges will decrease due to earlier snowmelt and increased evapotranspiration, while the changes in autumn depend on the climate scenario, location and hydrological characteristics such as lake percentage of the study catchments. The DBS method influences significantly the projected changes of the seasonal discharges and in some cases even the annual discharges of the scenarios with large temperature biases.

The changes in annual mean discharges between the control and 2051-2090 periods in all study catchments are between -15 and $26 \%$ (Table 6). For the period 2051-2090 HIRHAM-B produces the largest increases in annual mean discharges in all study catchments due to the largest increases in annual mean precipitation. Most of the scenarios show an increase in annual discharges, but especially for southern and central Finland some scenarios project decrease because the longer and warmer summers will cause a larger increase in evapotranspiration than the projected increase in precipitation.

In the study catchments all DBS-adjusted scenarios predict on average 2-4 weeks earlier snowmelt discharge peaks in spring for the 2051-2090 period compared to the control period 1961-2000. Figure 14 shows the results for three scenarios producing the largest variation of changes in mean discharges out of five scenarios used in this study. Because the snowmelt discharge peaks occur earlier, the recession flows in summer season decrease. The summer discharges decrease $20-50 \%$ in all scenarios except in Nilakka and Loimijoki in the HIRHAM-B-scenario, which predicts a greater increase in precipitation than the other scenarios. The decrease in mean summer discharges is caused by the increase of the annual evapotranspiration by $10-40 \%$ and lake evaporation by $10-80 \%$.

In addition to earlier spring discharge peaks and a decrease in summer discharges, all scenarios predict increase in winter discharges. The increase is more pronounced in the catchments of Loimijoki and Ounasjoki (40-150\%), which have lower lake percentage than Nilakka and Lentua, in which the 

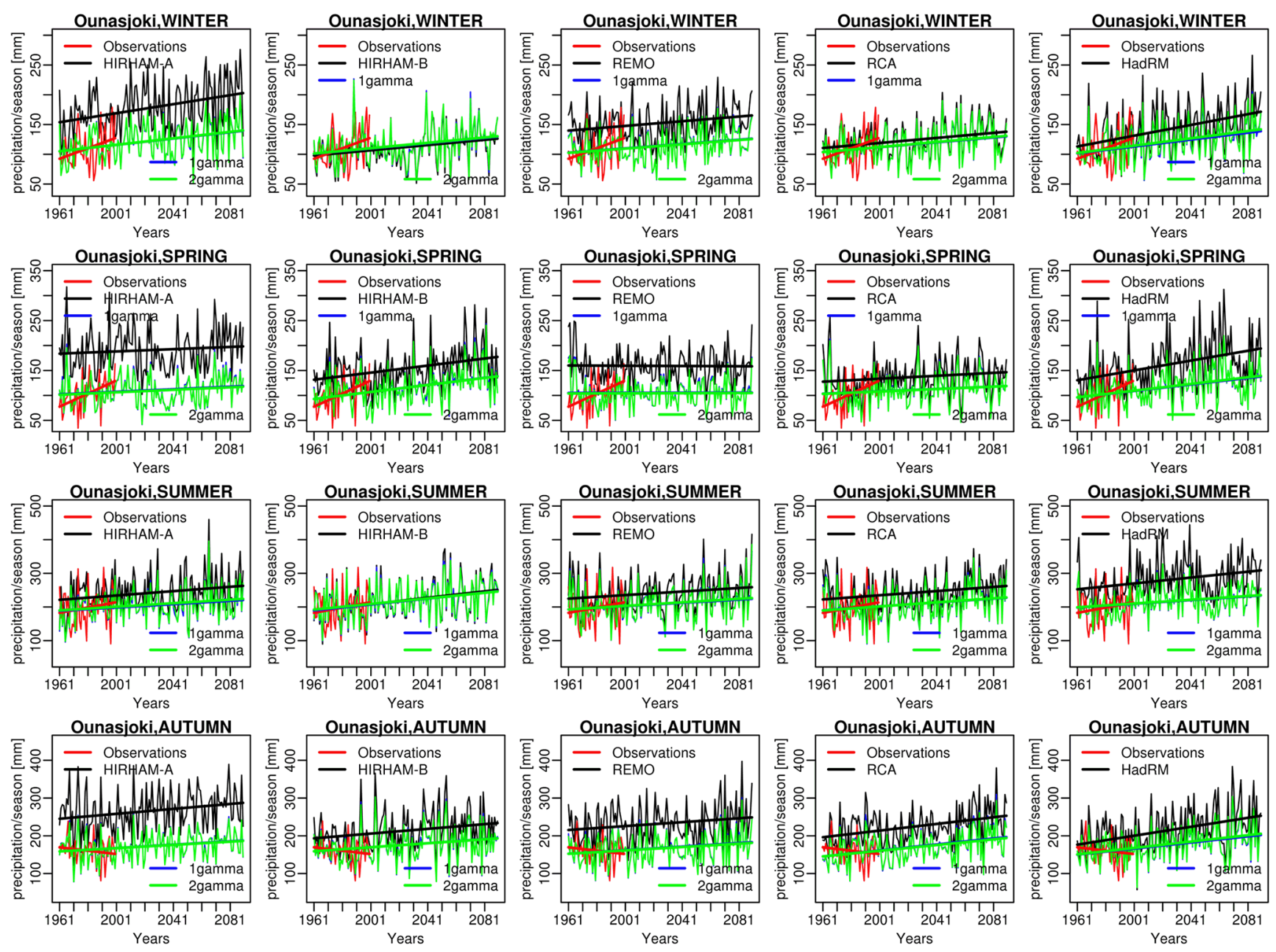

Figure 10. Seasonal trends in observed (red, 1961-2000) and RCM simulated seasonal precipitation accumulation in Ounasjoki catchment during 1961-2090. Uncorrected RCM precipitation in black, precipitation adjusted with single gamma in blue and with double gamma in green.

winter discharges increase $10-70 \%$, depending on the used scenario.

The results show an increase in autumn mean discharges in northern Finland, where the autumn runoff peaks - typical in southern Finland at present - become more frequent. In the catchments with large lake percentages in southern and central Finland, the autumn mean discharges decrease in all scenarios due to an increase in evapotranspiration and larger soil moisture deficit in the beginning of autumn. In the southern catchments with low lake percentages, the change in mean autumn discharges depends on the scenario. Different autumn precipitation changes between the scenarios are the main reason for different changes in autumn discharges, but also the soil moisture content after summer has an influence and varies depending on temperature and precipitation changes during summer.

The relative changes in mean discharges, MHQ and MNQ together with changes in mean maximum snow water equiv- alent (SWE), mean maximum soil moisture deficit (SMD), mean evapotranspiration (ET) and mean runoff $(R)$ in four test sites are shown in Fig. 15. The changes in annual high flows are mostly negative, due to decreased maximum SWE and consequently decreasing spring snowmelt floods. Only in the HIRHAM-B scenario the MHQ increase or remains the same in most test sites due to large increase in precipitation. The annual low flows decrease in southern Finland due to increased ET and maximum SMD, due to decrease in low flows in summer season. In northern Finland the annual MNQ increase, because the annual low flows normally occur in winter in the control period.

\section{Discussion}

All five climate scenarios used in this study contain systematic biases, and hydrological simulations with the uncorrected RCM data for the four study catchments therefore dif- 

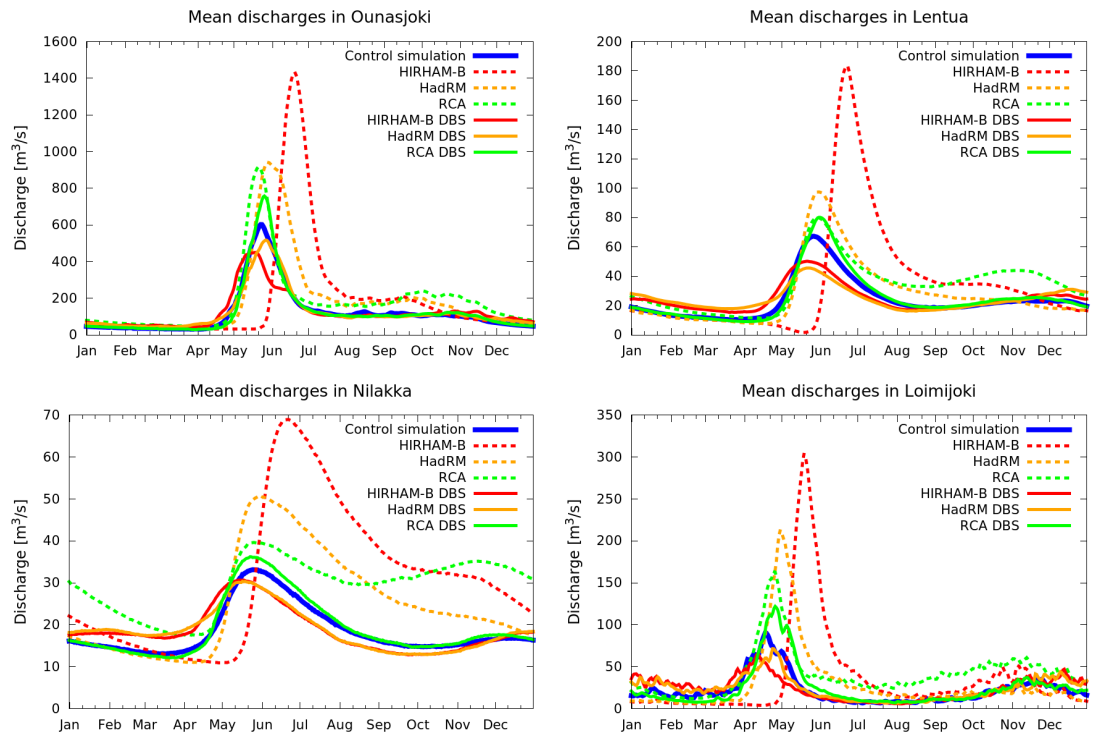

Figure 11. Hydrographs of simulated daily mean discharges in 1961-2000 with uncorrected RCM outputs (dashed lines) and corrected temperatures ( $T$ Gaussian) and precipitation ( $P$ double gamma) (solid lines) compared to control simulation discharges (blue line).
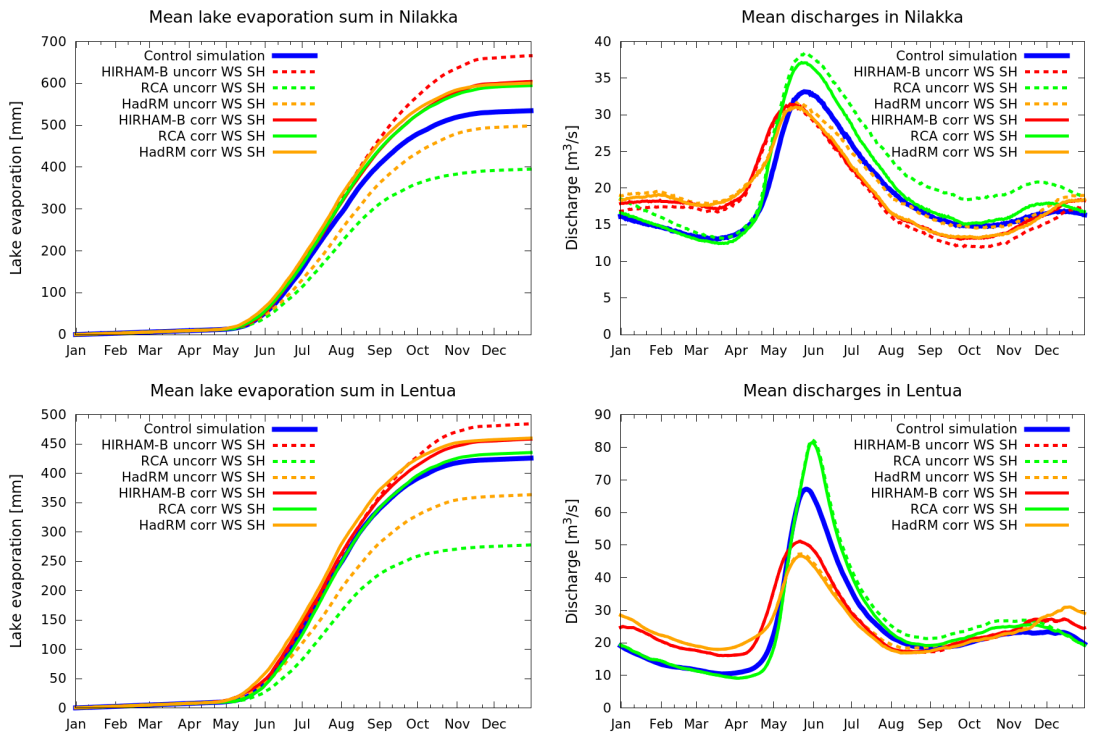

Figure 12. Model mean lake evaporation sums and simulated daily mean discharges of Lake Nilakka and Lake Lentua with RCA uncorrected WS and SH ( $T$ is Gaussian, $P$ is 2 gamma) in red, with corrected WS and SH ( $T$ is Gaussian, $P$ is double gamma) in green and control simulation in blue.

fer significantly from observations. Bias correction is necessary since RCM biases not only affect the absolute discharges, but also can influence the relative changes (Leander et al., 2008). As shown in the previous section the projected seasonal changes of the mean discharges in Finland are especially sensitive to RCM biases, because both the temperature and precipitation biases significantly influence the mean discharges.

Several studies comparing different bias correction methods have concluded that generally it is not possible to estab- lish one single method, which would outperform others in all circumstances, but some methods outperform other methods more frequently (Teutschbein and Seibert, 2012; Räisänen and Räty, 2013). Teutschbein and Seibert (2012) validated five different bias correction methods with $11 \mathrm{RCMs}$ and found DBS to perform best for temperature and precipitation. Räisänen and Räty (2013) found a combination of two quantile-quantile mapping (QM) methods to outperform each individual method when adjusting daily temperature from six RCMs. The disadvantage of the QM method is 
Table 5. Deviation of simulated annual and seasonal mean discharges (MQ) between observed, uncorrected and DBS-adjusted temperature (Gaussian) and precipitation (1 or 2 gamma) as input for hydrological simulations during control period 1961-2000 in \%. Values are shown for Loimijoki in southern Finland and Ounasjoki in northern Finland to demonstrate the spatial variation.

\begin{tabular}{|c|c|c|c|c|c|c|c|}
\hline & & Uncorrected & 1 Gamma & 2 Gamma & Uncorrected & 1 Gamma & 2 Gamma \\
\hline & & & Loimijoki & & & Ounasjoki & \\
\hline \multirow{5}{*}{$\stackrel{\bar{\varpi}}{\stackrel{\nabla}{*}}$} & HIRHAM-A & 85.7 & 9.5 & 10.1 & 104.2 & 3.3 & 3.2 \\
\hline & REMO & 58.0 & 12.3 & 11.8 & 78.6 & 5.7 & 5.1 \\
\hline & $\mathrm{RCA}$ & 89.0 & 12.7 & 11.5 & 48.5 & 4.9 & 4.4 \\
\hline & HadRM & 35.3 & 9.4 & 9.8 & 48.9 & 1.9 & 2.8 \\
\hline & HIRHAM-B & 63.3 & 10.0 & 9.8 & 56.6 & 2.9 & 3.1 \\
\hline \multirow{5}{*}{$\stackrel{\stackrel{\bar{\Xi}}{\Xi}}{\vdots}$} & HIRHAM-A & 86.7 & 22.9 & 22.1 & 85.7 & 12.5 & 12.6 \\
\hline & REMO & 16.4 & -22.4 & -21.7 & 73.8 & -7.9 & -8.3 \\
\hline & RCA & 33.5 & -12.1 & -12.3 & 67.5 & 3.8 & 3.2 \\
\hline & HadRM & -43.3 & 60.3 & 61.8 & 18.8 & 34.2 & 35.5 \\
\hline & HIRHAM-B & -46.1 & 79.1 & 79.0 & 19.1 & 46.7 & 46.7 \\
\hline \multirow{5}{*}{ 占 } & HIRHAM-A & 92.9 & 10.0 & 10.1 & -20.8 & -0.6 & -0.8 \\
\hline & REMO & 57.0 & 27.6 & 26.8 & 39.0 & 1.2 & 0.9 \\
\hline & $\mathrm{RCA}$ & 54.6 & 23.8 & 23.4 & 43.9 & 8.7 & 8.5 \\
\hline & HadRM & 67.7 & -9.5 & -9.5 & 12.2 & -2.5 & -2.0 \\
\hline & HIRHAM-B & 64.1 & -16.6 & -16.5 & -76.4 & 3.4 & 3.6 \\
\hline \multirow{5}{*}{ 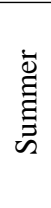 } & HIRHAM-A & 142.8 & 7.2 & 8.2 & 231.8 & 3.0 & 2.8 \\
\hline & REMO & 161.4 & 38.6 & 35.2 & 108.3 & 20.1 & 19.0 \\
\hline & $\mathrm{RCA}$ & 238.0 & 28.6 & 22.7 & 21.6 & 0.7 & 0.2 \\
\hline & HadRM & 140.5 & 4.9 & 3.7 & 97.0 & -0.7 & 0.3 \\
\hline & HIRHAM-B & 308.2 & -4.5 & -5.1 & 220.7 & -14.0 & -13.8 \\
\hline \multirow{5}{*}{$\underset{\Xi}{\Xi}$} & HIRHAM-A & 44.3 & -2.7 & -0.2 & 117.9 & 6.7 & 6.8 \\
\hline & REMO & 51.4 & 1.1 & 1.2 & 99.7 & -4.1 & -4.7 \\
\hline & RCA & 143.0 & 5.7 & 3.8 & 92.2 & 5.96 .0 & 4.7 \\
\hline & HadRM & -2.3 & 7.3 & 8.1 & 46.6 & 0.0 & 1.1 \\
\hline & HIRHAM-B & 57.7 & 11.5 & 11.0 & 32.6 & 10.8 & 11.2 \\
\hline
\end{tabular}

the need to extrapolate data in both ends of the QM function (e.g. Veijalainen et al., 2012; Räisänen and Räty, 2013). With DBS used in this study no extrapolation is needed because continuous distribution functions are used to adjust temperature and precipitation, and DBS is thus considered to be more sophisticated method.

Although bias correction methods usually improve the RCM simulations substantially, other uncertainties still remain, especially for future simulations. Biases in RCMs, changing trends due to different correction procedures, and non-stationarity of climate conditions have been investigated, e.g., by Teutschbein and Seibert (2013), Maraun (2012) and Maraun (2013). One disadvantage of bias correction is that the physical cause of precipitation and temperature bias is not taken into account. For instance a few degrees bias in temperature in winter affects the form of precipitation and snowmelt, which have significant impact on snow accumulation in hydrological models. A recent study by Räisänen et al. (2014) found that during the snowmelt period in the ECHAM5 model, the air temperature rarely rises above zero as long as there is snow on the ground, leading to too low temperatures during the snowmelt period. This study shows that even after the DBS adjustment the biases in the near-zero temperatures remain. Especially with the RCA and REMO, which were driven by boundary conditions from ECHAM5, these biases influence the magnitude of winter and spring runoff and floods in the hydrological model simulations. Maraun (2013) stated that bias correction can even deteriorate future simulations and increase the future bias especially in areas where biased responses of surface albedo, soil moisture or cloud cover affected RCM simulations. According to Maraun (2013), biases are however relatively stable and bias correction on average considerably improves climate scenarios.

Another source of uncertainties with bias correction methods is the stationarity assumption of model biases, which means that the RCM biases do not change in time and the same correction algorithm is assumed to be valid also for future conditions. However, Teutschbein and Seibert (2013) found DBS to perform relatively well even in changing climate conditions. They separated the coldest and warmest years as well as driest and wettest years to evaluate the per- 
Table 6. Relative changes (\%) in simulated annual and seasonal mean discharges (MQ) in Loimijoki and Ounasjoki between control period 1961-2000 and future period 2051-2090 using uncorrected and DBS-adjusted temperature (Gaussian) and precipitation (1 or 2 gamma).

\begin{tabular}{|c|c|c|c|c|c|c|c|}
\hline & & Uncorrected & 1 Gamma & 2 Gamma & Uncorrected & 1 Gamma & 2 Gamma \\
\hline & & & Loimijoki & & & Ounasjoki & \\
\hline \multirow{5}{*}{ 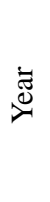 } & HIRHAM-A & -3.8 & -5.9 & -8.1 & 9.1 & 9.1 & 9.0 \\
\hline & REMO & 7.4 & 10.5 & 6.8 & -0.3 & -5.5 & -5.3 \\
\hline & $\mathrm{RCA}$ & 10.1 & 9.8 & 8.5 & 8.6 & 3.4 & 3.4 \\
\hline & HadRM & -6.8 & -6.8 & -7.6 & 15.3 & 5.0 & 6.1 \\
\hline & HIRHAM-B & 16.0 & 25.6 & 24.7 & 17.7 & 18.7 & 18.0 \\
\hline \multirow{5}{*}{ 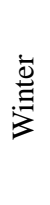 } & HIRHAM-A & 69.8 & 65.2 & 63.1 & 71.1 & 90.3 & 89.8 \\
\hline & REMO & 104.2 & 151.5 & 141.1 & 68.6 & 40.9 & 40.6 \\
\hline & RCA & 107.6 & 143.2 & 140.0 & 73.8 & 76.4 & 76.6 \\
\hline & HadRM & 204.5 & 37.7 & 36.5 & 76.1 & 128.9 & 131.8 \\
\hline & HIRHAM-B & 148.0 & 50.7 & 51.2 & 44.9 & 74.9 & 68.4 \\
\hline \multirow{5}{*}{ 品 } & HIRHAM-A & -25.6 & -32.2 & -33.3 & 134.3 & 26.0 & 26.0 \\
\hline & REMO & -18.6 & -21.9 & -23.4 & 24.2 & 20.2 & 19.8 \\
\hline & RCA & -21.9 & -23.8 & -23.7 & -1.1 & 11.5 & 12.0 \\
\hline & HadRM & -31.3 & -29.6 & -29.4 & 72.3 & 4.2 & 5.2 \\
\hline & HIRHAM-B & 21.2 & 17.5 & 14.7 & 206.3 & 16.5 & 18.1 \\
\hline \multirow{5}{*}{ 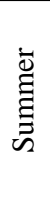 } & HIRHAM-A & -31.7 & -31.3 & -32.9 & -39.1 & -39.7 & -39.6 \\
\hline & REMO & -17.0 & -27.7 & -31.6 & -43.9 & -49.8 & -49.2 \\
\hline & RCA & -5.9 & -34.4 & -35.8 & -20.3 & -41.3 & -41.2 \\
\hline & HadRM & -25.4 & -23.3 & -25.4 & -38.5 & -49.7 & -49.3 \\
\hline & HIRHAM-B & -34.5 & 2.2 & 1.3 & -9.1 & -17.7 & -17.7 \\
\hline \multirow{5}{*}{$\begin{array}{l}\text { 䒠 } \\
\text { 㓂 }\end{array}$} & HIRHAM-A & -10.6 & -15.2 & -19.5 & 28.3 & 21.9 & 21.5 \\
\hline & REMO & 13.0 & 18.0 & 11.5 & 18.8 & 19.1 & 19.6 \\
\hline & $\mathrm{RCA}$ & 12.5 & 12.2 & 8.2 & 26.2 & 27.5 & 26.8 \\
\hline & HadRM & -13.0 & -22.1 & -23.7 & 37.5 & 23.0 & 24.4 \\
\hline & HIRHAM-B & 23.1 & 9.5 & 9.1 & 55.6 & 36.1 & 34.2 \\
\hline
\end{tabular}

formance of six different bias correction procedures under systematically varying climate conditions. They found DBS performed the best out of the studied bias correction methods under changing conditions and questioned the use of simple bias correction methods such as delta change and linear scaling. Without the possibility to validate future scenarios against observed values the best policy, according to Teutschbein and Seibert (2012), is to use an ensemble of RCMs with the best available bias correction method.

The current study shows that the effect of DBS adjustment on temperature and precipitation trends is generally small. But with a large bias in standard deviation of the uncorrected temperature data, the DBS may cause a significant change in temperature trends, increasing the uncertainty for the climate change projections. Also since the precipitation and temperature corrections are not interdependent, in some cases the bias in the snow accumulation remains considerably large, which leaves biases in spring discharges during the control period and certainly affects the relative changes in the future. Räisänen and Räty (2013) and Räty et al. (2014) concluded that since no single BC method outperforms others in all circumstances, the use of a few different but well-performing correction methods will give a more realistic range of uncertainty. In the hydrological studies the assessment of the performance should be based on the remaining biases in discharges during the control period to avoid unnecessary large uncertainty range and false conclusions about the impacts of climate change.

The DBS adjustment used in this study principally follows the method introduced by Yang et al. (2010). The method was tested using two versions of both temperature and precipitation corrections. The results show that the temperature correction in Finland works better without classification into wet and dry days. The classification is not straightforward and depends on season and area of investigation. A threshold value of observed precipitation, used to classify days to dry and wet, varies from $0 \mathrm{mmday}^{-1}$ (Teutschbein and Seibert, 2012) to as high as $1 \mathrm{~mm} \mathrm{day}^{-1}$ (Räty et al., 2014). In Finland RCMs produced too few days with $0 \mathrm{mmday}^{-1}$ and thus a threshold value to cut-off the spurious drizzle is needed. Nevertheless, a high threshold would cut too many precipitation days from both observations and RCMs and thus influence the precipitation and temperature distributions. On the other hand, when using a low threshold, e.g., $0.1 \mathrm{mmday}^{-1}$, only 

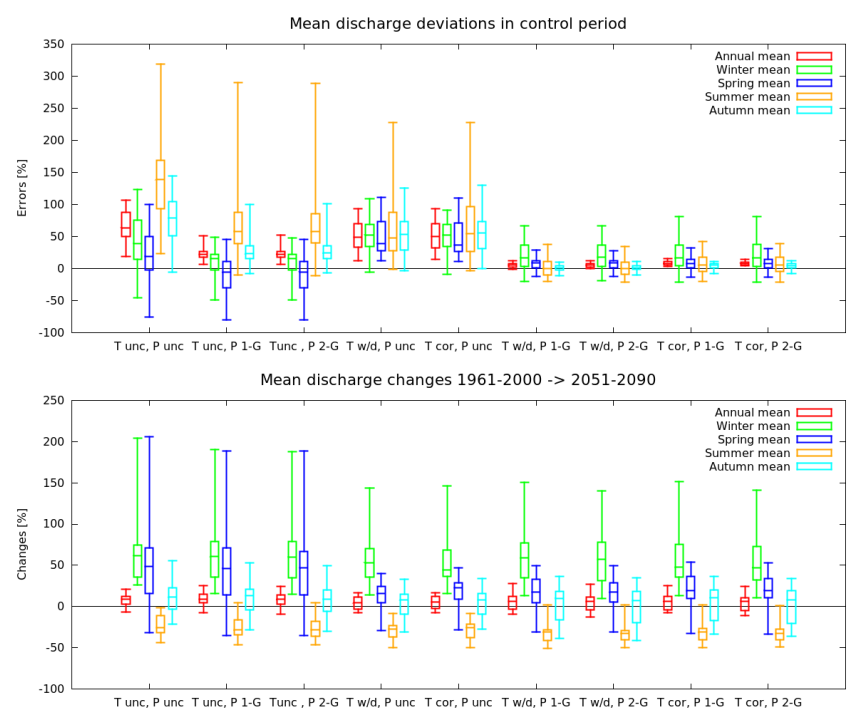

Figure 13. The minimum, maximum, 1st and 3rd quartile and median deviations of the simulated mean discharges with RCM data compared to control simulations (above) and climate change impacts (below) in four test sites using all five scenarios without corrections (unc), only with temperature correction ( $T \mathrm{w}-\mathrm{d}$ is wet-dry separation and $T$ cor is without separation) or precipitation corrections (1-G is single gamma and 2-G is double gamma) and with both temperature and precipitation corrections.

$20-30 \%$ of days in autumn and winter in Finland are considered to be dry. For precipitation distribution the removal of drizzle days is important, but for temperature it is questionable whether the simulated temperature for drizzle days represents the temperature for dry days. Separation of days according to wet-dry state reduces the number of days available for the temperature distribution on wet-dry days, which can cause biases in CDFs especially in the lower and upper tails of the distribution. Due to the tendency of wet-dry separation to produce too low minima and too high maxima the DBS approach without wet-dry separation produces better fit with observed values in most cases in Finland.

The DBS method with wet-dry separation roughly takes into account the correlation between temperature and precipitation, but precipitation is still adjusted without knowledge of temperature. It would not be rational to divide precipitation events according to near surface temperature since it does not determine the precipitation phase, but instead temperature at $850 \mathrm{hPa}$ could be used. Also separation according to weather types could take stratiform and torrential precipitation events better into account. The problem with these methods is the lack of comprehensive observational data and thus some reanalysis or other climate models should be used as observational data in the adjustment.

Two distributions, single and double gamma, were used for precipitation corrections. The double gamma distribution is expected to produce better fit with observed precipitation, compared to single gamma, due to better perfor- mance with torrential precipitation. However, depending on season and area of investigation single gamma distribution fitted observed values and RCM simulations better than double gamma distribution (e.g. RMSE 4.8-5.8 in single gamma and 5.4-5.6 in double gamma in Loimijoki and 2.8-3.0 in single gamma and 3.1 in double gamma in Ounasjoki in January). In these cases the area of investigation had not experienced many torrential precipitation events and a large part of the distribution consisted of drizzle days. Although double gamma usually reproduces torrential precipitation events better than single gamma, the cut-off value of $95 \%$ does not always produce the best results. At least for colder regions like Finland where torrential precipitation events are relatively rare, the cut-off value could be even higher (e.g. 98\%) to get better gamma fit also for the torrential values. After applying the $95 \%$ cut-off value, the torrential $5 \%$ means roughly precipitation values higher than $10 \mathrm{mmday}^{-1}$, although by definition $20 \mathrm{mmday}^{-1}$ is the threshold for torrential precipitation in Finland. In addition, the highest $5 \%$ of precipitation distribution does not in most cases produce real gamma function and thus the gamma fit might not be valid. One problem with double gamma distribution occurred near (below and above) the cut-off value for heavy precipitation because it caused discontinuity in the distribution and thus cumulated too much precipitation around this point. In Finland this means an increase in near $10 \mathrm{~mm} \mathrm{day}^{-1}$ precipitation amounts compared to observed values. Considering accumulated monthly mean precipitation amounts below and above the $95 \%$ cut-off value, we observed that in most cases DBS with double gamma accumulated more precipitation below the $95 \%$ cut-off value and less above the $95 \%$ cut-off value than single gamma (e.g. from -1.3 to $7.8 \%$ below the $95 \%$ cut-off value and from -26.2 to $0.7 \%$ above the $95 \%$ cut-off value in March in Loimijoki). Nevertheless, the monthly total accumulated precipitation is better represented by DBS with double gamma distribution when compared to observed values. For example DBS with double gamma gives $0.3-0.8 \%$ higher monthly mean precipitation accumulation than observations in March in Loimijoki and DBS with single gamma $0.3-1.3 \%$.

Precipitation varies considerably on spatial and temporal scales and thus to use either single or double gamma distribution alone is a somewhat rigid procedure. The importance of the torrential precipitation is more pronounced in the impact studies of flash floods and floods in small river catchments, which respond quickly to extreme precipitation. In the larger watersheds, the high discharges usually correlate better with 5-15-day extreme precipitation sums than torrential values due to the delay caused by soil moisture deficit, river transport, lake storage and wetlands inside the catchment. Thus, the tendency of double gamma correction to increase the near $10 \mathrm{~mm} \mathrm{day}^{-1}$ precipitation may deteriorate the DBS ability to reproduce the observed extreme discharges compared to single gamma distribution. A trade-off tool to see whether single or double gamma distribution fits better could be de- 

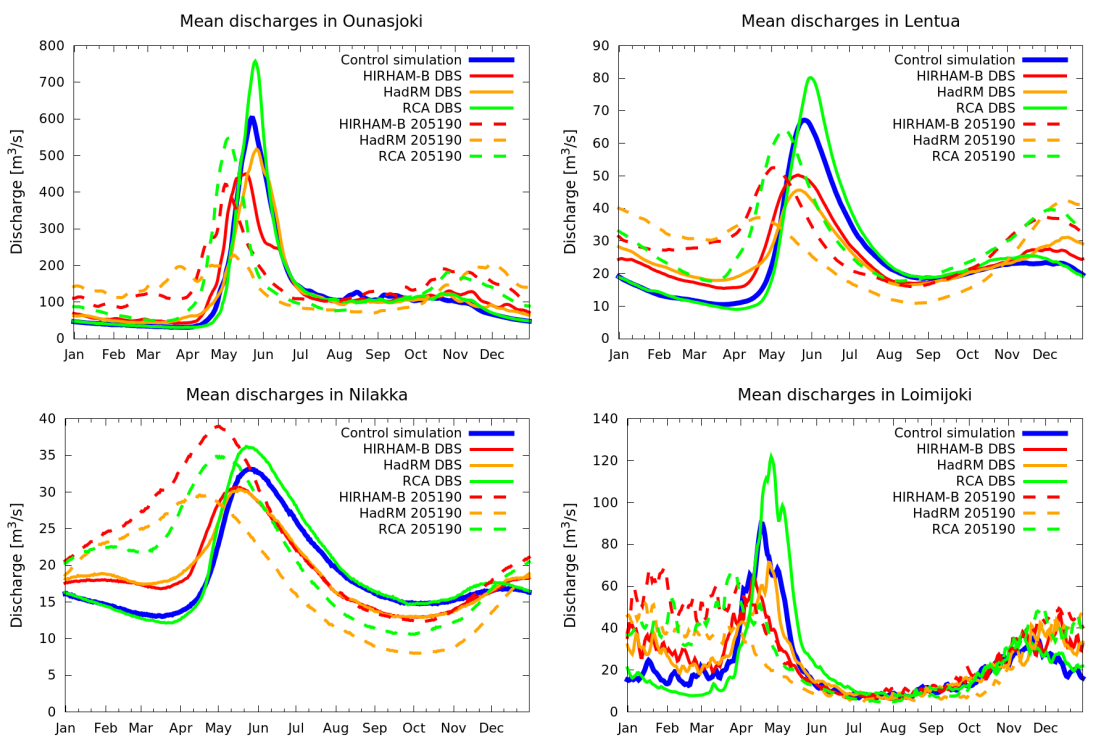

Figure 14. Hydrographs of simulated daily mean discharges with DBS-adjusted temperatures ( $T$ Gaussian without separation) and precipitation ( $P$ double gamma) of RCMs in 1961-2000 (solid lines) and in 2051-2090 (dashed lines) compared to control simulation discharges (blue line).

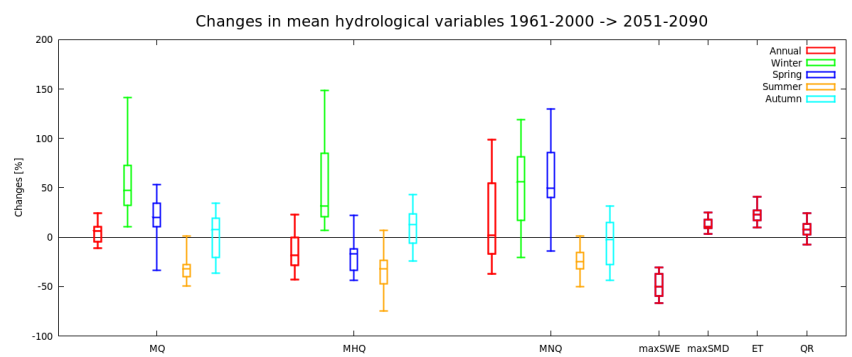

Figure 15. The minimum, maximum, 1 st and 3rd quartile and median changes by 2051-2090 period in mean discharges (MQ), mean high discharges (MHQ), mean low discharges (MNQ), mean maximum snow water equivalent (maxSWE), mean maximum soil moisture deficit (maxSMD), mean annual evapotranspiration (ET) and runoff $(R)$ in four test catchments and five scenarios with Gaussian and double gamma-adjusted RCM data.

veloped, but problems would occur when either observed or RCM simulated precipitation would not produce the same selection of gamma distribution.

Previously the most commonly used method to estimate climate change impacts on hydrology was the delta change method (e.g. Andréasson et al., 2004; Steele-Dunne et al., 2008; Veijalainen et al., 2010). Often a very simple version of this method, where only the monthly mean changes of temperature and precipitation from climate model simulations were used to modify the observed temperature and precipitation records, was used (Hay et al., 2000). Compared to delta change methods, the $\mathrm{BC}$ methods better preserve the variability in temperature and precipitation produced by the RCMs (Lenderink et al., 2007; Graham et al., 2007; Beldring et al., 2008; Yang et al., 2010). Veijalainen (2012) showed that with delta change and with the QM method, the changes in discharges for four catchments in Finland were similar for annual means. However, larger differences were found in flood estimates and in seasonal values. Especially during spring in northern Finland, the delta change method produced earlier snowmelt than the bias corrected RCM data. The changes in annual and seasonal discharges, as well as in timing of the spring discharge peaks, with DBS-adjusted RCM data of this study are in good agreement with results of the QM method used by Veijalainen et al. (2012). The result supports the idea to use both methods in future studies to better cover the uncertainty range caused by bias correction. On the other hand the extrapolation of the data in the QM method may increase the uncertainty of the climate projections.

The uncertainties in estimation of climate change impacts on hydrology remain large, since the process of estimation is complicated and each step contains uncertainties. The results show large differences between the five climate scenarios used in this study and climate scenarios have been shown to be a major source of the uncertainties in the climate change assessments (Steele-Dunne et al., 2008; Prudhomme and Davies, 2009). The hydrological model and its sub-models also cause uncertainties in the results. Hydrological model structure and parameter uncertainties are not considered, but other studies indicate that these can be substantial, although not among the largest sources of uncertainty (Steele-Dunne et al., 2008; Prudhomme and Davies, 2009). Within the WSFS hydrological model, the snow model and evapotranspiration model are the most important sub-models influencing the results, and the evaluation of different ver- 
sions of these sub-models would be required for the proper estimation of the hydrological model and overall estimation of the uncertainties.

\section{Summary and conclusions}

The use of bias corrected RCM data as input to impact models is becoming a common practice. The choice of bias correction method significantly affects estimation of climate change impacts on hydrology. The DBS algorithm has been shown to perform well under changing conditions and outperform other methods in many cases (Teutschbein and Seibert, 2012; Räty et al., 2014) and was therefore selected for this study. Two different DBS methods for temperature (with and without dry/wet day separation) and two for precipitation (single and double gamma distribution) were compared. This paper focuses on mean values of temperature, precipitation and discharges simulated with the hydrological model of WSFS in four catchments. The DBS adjustment significantly improves RCM data and simulated discharges compared to observations, but the magnitude of the biases of the uncorrected RCM data still influence the success of the DBS method.

Both gamma distributions used in the DBS method for precipitation provide reasonable results for Finland, where precipitation extremes are moderate in all seasons. Double gamma distribution reproduces monthly precipitation amounts and torrential values better than single gamma distribution, but the cut-off value in 95th percentile is too low in some cases and it could be better to determine specifically for northern climate conditions. For temperature, the small fraction of dry days during some seasons affects the DBS temperature adjustment with dry/wet separation, and thus for temperature the method without dry/wet separation performs better. With most scenarios the DBS method preserves temperature and precipitation trends projected by uncorrected RCMs data sufficiently well. However, in cases when the simulated seasonal cycle of precipitation in RCM is not correct, the DBS adjustment changes the trend more than for cases with a correct seasonal cycle. Also, too narrow standard deviation of uncorrected RCM data compared to observed deviation leads to increased temperature trends after DBS adjustment with two scenarios. The cold bias found in RCMs during snowmelt can be reduced by DBS method, but the remaining biases are found to influence the timing of snowmelt and the magnitude of winter and spring discharges in hydrological simulations.

The projected changes in annual mean discharges by 2051-2090 are moderate, but seasonal distribution of discharges will change significantly. The most notable changes are increasing winter discharges, decreased and earlier spring discharge peaks, and decreasing summer discharges due to longer and warmer summer and increased evapotranspiration. The autumn discharges are projected to increase in northern Finland and decrease in the catchments with high lake percentage in southern Finland. The different RCMs produce a wide range of variability on magnitude of the changes. Contrary to the other scenarios used in this study, the HIRHAM-B scenario produces an increase in summer discharges due to greater precipitation increase. Also the effect of different scenarios on mean autumn discharge in the fast responding southern catchments is scenario dependent.

For relative changes in future discharges, the bias correction mainly affects the seasonal results. The differences between changes in seasonal discharges with corrected and uncorrected RCM data are significant especially in the scenarios with large temperature biases. The correct seasonal changes are important when any detailed analysis of adaptation strategies, for example in lake regulation rules or flood risk analysis, are considered. Especially the extremes - floods and droughts - are sensitive to both temperature and precipitation biases and without bias correction even the results of relative changes in floods can be misleading. The impact of the bias correction on precipitation extremes and on simulated extreme discharges will be examined in the next phase of this study and published in a separate paper.

Since the choice of the bias correction method influences the results and the best method cannot usually be assessed, an ensemble of bias correction methods to incorporate this uncertainty to the other sources of uncertainty such as choice of emission scenario, climate or hydrological model could be used in the future. However, the evaluation of sufficiently well-performing bias correction methods is required to avoid unrealistic results in the climate change impact assessments. The remaining biases in temperature and precipitation data, independent adjustments for meteorological variables or changing temperature and precipitation trends in some climate scenarios after the DBS adjustment cause additional uncertainty in the hydrological simulations and these should be considered when the results are interpreted.

Acknowledgements. This study was carried out within the project Climate Change and Water Cycle: Effect to Water Resources and their Utilization in Finland (ClimWater) (no. 140930) financed by the Finnish Academy as part of the Research Programme for climate change FICCA. The ENSEMBLES data used in this work were funded by the EU FP6 Integrated Project ENSEMBLES (contract number 505539) whose support is gratefully acknowledged.

Edited by: E. Morin

\section{References}

Andréasson, J., Bergström, S., Carlsson, B., Graham, L., and Lindström, G.: Hydrological change - climate change impact simulations for Sweden, Ambio, 33, 228-234, 2004.

Beldring, S., Engen-Skaugen, T., Førland, E., and Roald, L.: Climate change impacts on hydrological processes in Norway based 
on two methods for transferring RCM results to meteorological station sites, Tellus A, 60, 439-450, 2008.

Bergström, S.: Development and application of a conceptual runoff model for Scandinavian catchments, SMHI, Norrköping, Report RHO No. 7, 134 pp., 1976.

Castro, M., Gallardo, C., Jylhä, K., and Tuomenvirta, H.: The use of a climate-type classification for assessing climate change effects in Europe from an Ensemble of nine regional climate models, Climatic Change, 81, 329-341, doi:10.1007/s10584-006-9224$1,2007$.

Christensen, J. H., Boberg, F., Christensen, O. B., and LucasPicher, P.: On the need for bias correction of regional climate change projections of temperature and precipitation, Geophys. Res. Lett., 35, L20709, doi:10.1029/2008GL035694, 2008.

Finnish Environment Institute: available at: www.environment.fi/ waterforecast/, last access: 10 January 2015.

Førland, E. J., Allerup, P., Dahlström, B., Elomaa, E., Jónsson, T., Madsen, H., Perälä, J., Rissanen, P., Vedin, H., and Vejen, F.: Manual for Operational Correction of Nordic Precipitation Data, Norwegian Meteorol. Inst., Oslo, Report 24/96 KLIMA, 66 pp., 1996.

Graham, L. P., Andréasson, J., and Carlsson, B.: Assessing climate change impacts on hydrology from an ensemble of regional climate models, model scales and linking methods - a case study on the Lule River Basin, Climatic Change, 81, 293-307, 2007.

Hay, L. E., Wilby, R. L., and Leavesley, G. H.: A comparison of delta change and downscaled GCM scenarios for three mountainous basins in the United States, Journal of American Water Resources Association (JAWRA), 36, 387-397, 2000.

Hewitson, B. C. and Crane, R. G.: Climate downscaling: techniques and application, Clim. Res., 7, 85-95, 1996.

Huttunen, I., Lehtonen, H., Huttunen, M., Piirainen, V., Korppoo, M., Veijalainen, N., Viitasalo, M., and Vehvilänen, B.: Effects of climate change and agricultural adaptation on nutrient loading from Finnish catchments to the Baltic Sea, Sci. Total Environ., 529, 168-181, 2015.

Hyvärinen, V., Solantie, R., Aitamurto, S., and Drebs, A.: Suomen vesitase 1961-1990 valuma-alueittain, Vesi- ja ympäristöhallitus, Helsinki, Vesi- ja ympäristöhallinnon julkaisuja - sarja A 220, 1995.

Jakkila, J., Vento, T., Rousi, T., and Vehviläinen, B.: SMOS soil moisture data validation in the Aurajoki watershed, Finland, Hydrol. Res., 45, 684-702, doi:10.2166/nh.2013.234, 2014.

Jylhä, K., Tuomenvirta, H., Ruosteenoja, K., Niemi-Hugaerts, H., Keisu, K., and Karhu, J. A.: Observed and projected future shifts of climate zones in Europe and their use to visualize climate change information, Weather, Climate and Society, 2, 148-167, doi:10.1175/2010WCAS1010.1, 2009a.

Jylhä, K., Ruosteenoja, K., Räisänen, J., Venäläinen, A., Ruokolainen, L., Saku, S., and Seitola, T.: Arvioita Suomen muuttuvasta ilmastosta sopeutumistutkimuksia varten, ACCLIMhankkeen raportti 2009, Ilmatieteen laitos, Helsinki, Raportteja 2009:4, 2009b.

Korhonen, J. and Kuusisto, E.: Long-term changes in the discharge regime in Finland, Hydrol. Res., 41, 253-268, 2010.

Leander, R., Buishand, T. A., van den Hurk, B. J. J. M., and de Wit, M. J. M.: Estimation of changes in flood quintiles of the river Meuse from resampling of regional climate model output, J. Hydrol., 351, 331-343, 2008.
Lenderink, G., Buishand, A., and van Deursen, W.: Estimates of future discharges of the river Rhine using two scenario methodologies: direct versus delta approach, Hydrol. Earth Syst. Sci., 11, 1145-1159, doi:10.5194/hess-11-1145-2007, 2007.

Maraun, D.: Nonstationarities of regional climate model biases in European seasonal temperature and precipitation sums, Geophys. Res. Lett., 39, L06706, doi:10.1029/2012GL051210, 2012.

Maraun, D.: Bias correction, quantile mapping, and downscaling: revisiting the inflation issue, J. Climate, 26, 2137-2143, doi:10.1175/JCLI-D-12-00821.1, 2013.

Nash, J. E. and Sutcliffe, J. V.: River forecasting through conceptual models 1: a discussion of principles, J. Hydrol., 10, 282-290, 1970.

Perälä, J. and Reuna, M.: Lumen vesiarvon alueellinen ja ajallinen vaihtelu Suomessa, Vesi- ja ympäristöhallitus, Helsinki, Vesi- ja Ympäristöhallinnon julkaisuja - sarja A 56, 1990.

Prudhomme, C. and Davies, H.: Assessing uncertainties in climate change impact analyses on the river flow regimes in the UK. Part 2: Future climate, Climatic Change, 93, 197-222, 2009.

Räisänen, J. and Räty, O.: Projections of daily mean temperature variability in the future: cross-validation tests with ENSEMBLES regional climate simulations, Clim. Dynam., 41, 15531568, doi:10.1007/s00382-012-1515-9, 2013.

Räisänen, P., Luomaranta, A., Järvinen, H., Takala, M., Jylhä, K., Bulygina, O. N., Luojus, K., Riihelä, A., Laaksonen, A., Koskinen, J., and Pulliainen, J.: Evaluation of North Eurasian snow-off dates in the ECHAM5.4 atmospheric general circulation model, Geosci. Model Dev., 7, 3037-3057, doi:10.5194/gmd-7-30372014, 2014.

Räty, O., Räisänen, J., and Ylhäisi, J.: Evaluation of delta change and bias correction methods for future daily precipitation: intermodel cross-validation using ENSEMBLES simulations, Clim. Dynam., 42, 2287-2303, 2014.

Rauscher, S. A., Coppola, E., Piani, C., and Giorgi, F.: Resolution effects on regional climate model simulations of seasonal precipitation over Europe, Clim. Dynam., 35, 685-711, doi:10.1007/s00382-009-0607-7, 2010.

Resio, D. T. and Vincent, C. L.: Estimation of winds over the great lakes, J. Waterw. Port C. Div., 103, 265-283, 1977.

Ruosteenoja, K., Räisänen, J., and Pirinen, P.: Projected changes in thermal seasons and the growing season in Finland, Int. J. Climatol., 31, 1473-1487, doi:10.1002/joc.2171, 2011.

Steele-Dunne, S., Lynch, P., McGrath, R., Semmler, T., Wang, S., Hanfin, J., and Nolan, P.: The impacts of climate change on hydrology in Ireland, J. Hydrol., 356, 28-45, 2008.

Taskinen, A.: Operational correction of daily precipitation measurements in Finland, Boreal Environ. Res., in review, 2015.

Teutschbein, C. and Seibert, J.: Bias correction of regional climate model simulations for hydrological climate-change impact studies: review and evaluation of different methods, J. Hydrol., 456457, 12-29, 2012.

Teutschbein, C. and Seibert, J.: Is bias correction of regional climate model (RCM) simulations possible for nonstationary conditions?, Hydrol. Earth Syst. Sci., 17, 5061-5077, doi:10.5194/hess-17-5061-2013, 2013.

van der Linden, P. and Mitchell, J. F. B. (Eds.): ENSEMBLES: Climate Change and its Impacts: Summary of Research and Results from the ENSEMBLES Project, Met Office Hadley Centre, Exeter EX1 3PB, UK, 160 pp., 2009. 
van Pelt, S. C., Kabat, P., ter Maat, H. W., van den Hurk, B. J. J. M., and Weerts, A. H.: Discharge simulations performed with a hydrological model using bias corrected regional climate model input, Hydrol. Earth Syst. Sci., 13, 2387-2397, doi:10.5194/hess13-2387-2009, 2009.

Vehviläinen, B.: Snow Cover Models in Operational Watershed Forecasting, Publications of Water and Environment Research Institute, 11, National Board of Waters and the Environment, Helsinki, 1992.

Vehviläinen, B. and Huttunen, M.: Climate change and Water Resources in Finland, Boreal Environ. Res., 2, 3-18, 1997.

Vehviläinen, B., Huttunen, M., and Huttunen, I.: Hydrological forecasting and real time monitoring in Finland: the watershed simulation and forecasting system (WSFS), in: Innovation, Advances and Implementation of Flood Forecasting Technology, Conference Papers, Troms $\varnothing$, Norway, 17-19 October 2005.
Veijalainen, N.: Estimation of climate change impacts on hydrology and floods in Finland, PhD thesis, Aalto University, Espoo, Finland, Doctoral dissertations 55/2012, 211 pp., 2012.

Veijalainen, N., Lotsari, E., Alho, P., Vehviläinen, B., and Käyhkö, J.: National scale assessment of climate change impacts on flooding in Finland, J. Hydrol., 391, 333-350, 2010.

Veijalainen, N., Korhonen, J., Vehviläinen, B., and Koivusalo, H.: Modelling and statistical analysis of catchment water balance and discharge in Finland in 1951-2099 using transient climate scenarios, Journal of Water and Climate Change, 3, 55-78, doi:10.2166/wcc.2012.012, 2012.

Wood, A. W., Leung, L. R., Shidhar, V., and Lettenmaier, D. P.: Hydrological implications of dynamical and statistical approaches to downscale climate model outputs, Climatic Change, 62, 189216, 2004

Yang, W., Andréasson, J., Graham, L. P., Olsson, J., Rosberg, J., and Wetterhall, F.: Distribution-based scaling to improve usability of regional climate model projections for hydrological climate change impacts studies, Hydrol. Res., 41, 211-229, doi:10.2166/nh.2010.004, 2010. 